\title{
Central Activation of the A1 Adenosine Receptor (A1AR) Induces a Hypothermic, Torpor-Like State in the Rat
}

\author{
Domenico Tupone, Christopher J. Madden, and Shaun F. Morrison \\ Department of Neurological Surgery, Oregon Health \& Science University, Portland, Oregon 97239-3098
}

\begin{abstract}
Since central activation of A1 adenosine receptors (A1ARs) plays an important role in the induction of the hypothermic and hypometabolic torpid state in hibernating mammals, we investigated the potential for the A1AR agonist N6-cyclohexyladenosine to induce a hypothermic, torpor-like state in the (nonhibernating) rat. Core and brown adipose tissue temperatures, EEG, heart rate, and arterial pressure were recorded in free-behaving rats, and c-fos expression in the brain was analyzed, following central administration of N6-cyclohexyladenosine. Additionally, we recorded the sympathetic nerve activity to brown adipose tissue; expiratory $\mathrm{CO}_{2}$ and skin, core, and brown adipose tissue temperatures; and shivering EMGs in anesthetized rats following central and localized, nucleus of the solitary tract, administration of N6-cyclohexyladenosine. In rats exposed to a cool $\left(15^{\circ} \mathrm{C}\right)$ ambient temperature, central A1AR stimulation produced a torpor-like state similar to that in hibernating species and characterized by a marked fall in body temperature due to an inhibition of brown adipose tissue and shivering thermogenesis that is mediated by neurons in the nucleus of the solitary tract. During the induced hypothermia, EEG amplitude and heart rate were markedly reduced. Skipped heartbeats and transient bradycardias occurring during the hypothermia were vagally mediated since they were eliminated by systemic muscarinic receptor blockade. These findings demonstrate that a deeply hypothermic, torpor-like state can be pharmacologically induced in a nonhibernating mammal and that recovery of normothermic homeostasis ensues upon rewarming. These results support the potential for central activation of A1ARs to be used in the induction of a hypothermic, therapeutically beneficial state in humans.
\end{abstract}

\section{Introduction}

Mammals that are capable of natural torpor cope with the harsh environmental conditions of food scarcity combined with cold exposure by drastically reducing their core body temperature (TCORE) and their metabolic energy requirements (Melvin and Andrews, 2009). The neural and humoral mechanisms that trigger and maintain this hypothermic torpid state and that reset cellular and organismal homeostasis to allow survival during the deep hypothermia characteristic of torpor and hibernation remain largely unknown (Geiser, 2004). However, a renewed interest in the potential to induce a hypothermic, hypometabolic state in nonhibernating mammals, including humans, has been sparked by the therapeutic benefits accruing if a sustained hypothermia, and the accompanying marked reductions in cellular metabolism and oxygen demand, can be applied in the immediate period following cardiac or brain ischemia (Zhao et al., 2007; Yenari and Han, 2012).

As a direct byproduct of ATP metabolism, adenosine could provide a measure of an organism's overall metabolic state and

Received May 10, 2013; revised July 26, 2013; accepted July 30, 2013.

Author contributions: D.T., C.J.M., and S.F.M. designed research; D.T. and S.F.M. performed research; D.T. analyzed data; D.T., C.J.M., and S.F.M. wrote the paper.

This work was supported by National Institutes of Health Grant NS040987 (S.F.M.), a Collins Medical Trust grant (D.T.), and an American Heart Association grant-in-aid (C.J.M.). We thank Rubing Xing for his contributions to the histological and immunohistochemical data and Dr. Martina Mancini for her contribution in the statistical analysis. The authors declare no competing financial interests.

Correspondence should be addressed to Domenico Tupone, PhD, Department of Neurological Surgery, Oregon Health \& Science University, 3181 SW Sam Jackson Park Road, Portland, OR 97239-3098. E-mail: tupone@ohsu.edu. DOI:10.1523/JNEUROSCI.1980-13.2013

Copyright $\odot 2013$ the authors $\quad 0270-6474 / 13 / 3314512-14 \$ 15.00 / 0$ has been an attractive candidate for triggering the hypometabolic torpid state. Indeed, central A1 adenosine receptor (A1AR) activation is necessary for the induction and maintenance of natural torpor (Jinka et al., 2011; Iliff and Swoap, 2012), and central administration of adenosine $5^{\prime}$-monophosphate (AMP) elicits a marked, A1AR-dependent hypothermia in mice (Muzzi et al., 2013). Although expressed throughout the CNS, adenosine receptors are strongly localized in the intermediate nucleus of the solitary tract (iNTS) (Carrettiero and Fior-Chadi, 2004; Pickel et al., 2006), the primary termination site of visceral afferents controlling cardiovascular, respiratory, gustatory, and metabolic function (Andresen and Kunze, 1994; Grill and Hayes, 2012). Indeed, the iNTS has received considerable attention for its role in the regulation of body temperature and metabolism (Székely, 2000; Cao et al., 2010; Grill and Hayes, 2012; Kong et al., 2012) and iNTS neurons are in a unique position to integrate central and peripheral energy-related signals (Blevins et al., 2004).

Fundamental to the induction and maintenance of a deeply hypothermic state is an abrogation of the cold-defense mechanisms of thermogenesis and cutaneous vasoconstriction (Sessler, 2009). Although indirect indices support a potential role for an active suspension of cold-defensive brown adipose tissue (BAT) and shivering thermogenesis in the induction and maintenance of torpor (Cannon and Nedergaard, 2004), this has not been directly demonstrated. Since A1AR activation plays a key role in torpor induction, we tested the hypothesis that activating A1ARs in the rat CNS could trigger a hypometabolic and a torpor-like state in this nonhibernating species. From measurements of the thermal effectors, BAT and shivering thermogenesis, and cutane- 
ous vasoconstriction, and of cardiovascular variables and the EEG, we demonstrate that central administration of an A1AR agonist can, indeed, induce a hypothermic, hypometabolic, torpor-like state in the rat. We also identified the iNTS as the brain region responsible for the central A1AR-mediated inhibition of the cold-defensive thermogenesis that allows the body core temperature to fall.

\section{Materials and Methods}

Animals

Male Wistar rats (300-400 g; Charles River Laboratories) were maintained in a standard $12 \mathrm{~h}$ light/dark cycle (light on at 9:00 A.M.) with ad libitum access to standard chow and water. Experiments were performed in accordance with the Guide for the Care and Use of Laboratory Animals, Eighth Edition (National Research Council, National Academies Press, 2010) and protocols were approved by the Institutional Animal Care and Use Committee of Oregon Health \& Science University.

\section{Surgical procedure for physiology and c-fos}

anatomical experiments

Rats were anesthetized with $2 \%$ isoflurane in $100 \% \mathrm{O}_{2}$ and placed in a stereotaxic frame with the incisor bar positioned $-4 \mathrm{~mm}$ below interaural zero. A burr hole was drilled through the parietal bone and an intracerebroventricular guide cannula (guide, C315G-26GA; internal, C315I33GA; PlasticsOne) was positioned in the left lateral ventricle (bregma, $-2 \mathrm{~mm} ; 1.6 \mathrm{~mm}$ lateral to the midline; dura, $-4 \mathrm{~mm}$ ) and secured to the bone with screws and dental acrylic. Reflux of CSF from the guide cannula verified the correct placement of the intracerebroventricular cannula. A burr hole was drilled through the interparietal bone and $120 \mathrm{nl}$ of the neuronal retrograde tracer, cholera toxin subunit $\mathrm{B}(\mathrm{CTb}, 1 \mathrm{mg} / \mathrm{ml})$, was pneumatically ejected from a glass pipette ( $30 \mu \mathrm{m}$ tip) stereotaxically positioned in the rostral raphe pallidus ( $\mathrm{rRPa}$; lambda, $-3 \mathrm{~mm} ; 0.0 \mathrm{~mm}$ lateral to the midline; dura, $-9.2 \mathrm{~mm}$ ). A temperature recording device (IPTT-300, Bio Medic Data Systems) was implanted in the interscapular BAT and EKG needle electrodes were placed subcutaneously near the axilla.

\section{Surgical procedure for BAT sympathetic nerve activity recording and shivering experiments}

Rats were anesthetized initially with $3 \%$ isoflurane in $100 \% \mathrm{O}_{2}$ and transitioned to urethane $(0.8 \mathrm{~g} / \mathrm{kg})$ and chloralose $(80 \mathrm{mg} / \mathrm{kg})$ following cannulation of a femoral artery and vein. Heart rate (HR) was derived from the femoral arterial pressure (AP) signal. Animals were positioned prone in a stereotaxic frame with the incisor bar $-11 \mathrm{~mm}$ below interaural zero and a spinal clamp installed on the T10 vertebra to maintain the spine in a rigid and elevated position that provides (1) a constant and horizontal positioning of the caudal brainstem, (2) an optimal oil pool within which to record BAT sympathetic nerve activity (SNA), and (3) a reduced potential for respiratory-related artifacts in the BAT SNA recording. The medial portion of the occipital bone was removed and the atlantooccipital membrane was opened to visualize the calamus scriptorius at the caudal tip of the fourth ventricle. Rats were paralyzed with D-tubocurarine $(0.3 \mathrm{mg}$ initial dose, $0.1 \mathrm{mg} / \mathrm{h}$ supplements) and artificially ventilated via a tracheal cannula with $100 \% \mathrm{O}_{2}(60-70$ cycles $/ \mathrm{min}$, tidal volume 3-3.5 ml). Small adjustments in minute ventilation were made to maintain basal mixed-expired $\mathrm{CO}_{2}$ levels between 3.0 and $4.5 \%$. Thermocouples (Physitemp Instruments with Sable Systems International meter) were placed on the shaved abdominal skin to measure skin temperature (TskiN) beneath a water-perfused blanket wrapped around the rat's trunk, $6 \mathrm{~cm}$ into the rectum to measure TCORE, and into the medial aspect of the left interscapular BAT (iBAT) pad to measure BAT temperature (TВAT). TCORE was maintained at $\sim 37^{\circ} \mathrm{C}$ by perfusing the water blanket with warm water. As required for specific experimental protocols, TsKin and TCORE were adjusted by changing the temperature of the water perfusing the thermal blanket: cooling elicited a basal BAT SNA and warming inhibited BAT SNA via stimulation of skin thermal receptors (Morrison et al., 2008).

Postganglionic BAT SNA was recorded from the central cut end of a small nerve bundle dissected from the ventral surface of the right iBAT pad after dividing the fat pad along the midline and reflecting it laterally.
Nerve activity was recorded with bipolar hook electrodes, filtered (1-300 $\mathrm{Hz}$ ), and amplified (20,000×; Cyberamp 380, Molecular Devices). Evoked nerve potentials following electrical stimulation of the sympathetic premotor neurons in $\mathrm{rPa}$ (relative to calamus scriptorius: +3.0 $\mathrm{mm}$ anterior, $0.0 \mathrm{~mm}$ lateral, $-2.5 \mathrm{~mm}$ ventral) verified the viability of the isolated BAT nerve.

The surgical preparation for experiments in which shivering EMGs were recorded was similar to that for BAT SNA recordings except for the following. Rats were anesthetized initially with $3 \%$ isoflurane in $100 \% \mathrm{O}_{2}$ and transitioned to a continuous intravenous infusion of inactin $(85$ $\mathrm{mg} / \mathrm{ml}$ at $0.2 \mathrm{ml} / \mathrm{h}$ ). Rats were artificially ventilated but were not paralyzed to preserve the recording of the EMGs. EMGs were recorded with bipolar electrodes inserted into the nuchal (neck), masseter (jaw), and left gastrocnemius (leg) muscles.

\section{Surgical procedure for experiments in awake, free-behaving rats}

Rats were anesthetized with $2 \%$ isoflurane in $100 \% \mathrm{O}_{2}$ and implanted with electrodes for chronic recordings of the EEG (reference electrode through the frontal bone, active electrode through the parietal bone), the nuchal EMG, and the EKG. Miniature thermistors (NTC surface mount thermistor, NB21L00223JBB, Farnell) were implanted for recording Tват (from iBAT) and TCORE (from the mediastinic cavity). A telemetric sensor (PA-C40, Data Sciences International) was placed in the femoral artery for AP recording and a microcannula in the lateral ventricle for intracerebroventricular injection of drugs. EKG electrodes were positioned on the xiphoid process and in the mediastinic cavity (Sgoifo et al., 1996). All electrode wires were tunneled subcutaneously and connected to a 12-pin electronic connector, which, along with the intracerebroventricular guide cannula, was secured to the skull with screws and dental acrylic.

At the end of the surgical procedure, rats were treated with buprenorphine $(0.1 \mathrm{mg} / \mathrm{kg})$, penicillin $\mathrm{G}$ (40 kilounits $/ \mathrm{kg}$ ) and hydrated with isotonic saline $(5 \mathrm{ml}$, s.c.). Each rat recovered for $7 \mathrm{~d}$ in a temperature-controlled recording chamber at a thermocouple-measured ambient temperature (ТАмB) of $25^{\circ} \mathrm{C}$, received daily meloxicam $(1 \mathrm{mg} / \mathrm{kg}$ orally) for $5 \mathrm{~d}$ to reduce postsurgical inflammation, and was acclimated to the recording tether for the $2 \mathrm{~d}$ before the experimental recording sessions.

\section{Drug injection procedure}

Intraparenchymal nanoinjections of drugs were accomplished via glass micropipettes (outer tip diameter, 20-30 $\mu \mathrm{m}$ ) and were given over 5-10 s, using a pressure injection system (model IIe, Toohey) allowing nanoinjection volumes ( 60 or $120 \mathrm{nl}$ ) to be determined from the displacement of the fluid meniscus in the micropipette. For multiple nanoinjections at the same site, the micropipette was retracted vertically, emptied, rinsed with saline, refilled, and then repositioned to the original dorsoventral coordinate. The microinjection sites were marked by pressure microinjection of fluorescent polystyrene microspheres (1:10 dilution of FluoroSpheres, F8797, F8801, or F8803, Invitrogen). After physiological recordings, rats were perfused transcardially with $0.9 \%$ isotonic saline, followed by $4 \%$ paraformaldehyde in PBS. The brains were removed, postfixed ( $2 \mathrm{~h}$ ), equilibrated overnight in $20 \%$ sucrose and $0.01 \%$ sodium azide, and sectioned ( $30 \mu \mathrm{m}$ coronal sections) to localize the fluorescent spots indicating the centers of the injection sites. All the coordinates used for the brain intraparenchymal injections were adapted from a rat brain atlas (Paxinos and Watson, 2007).

For intracerebroventricular injections, the internal cannula was connected to a $25 \mu \mathrm{l}$ gas-tight syringe (Hamilton) positioned in the implanted guide cannula. Over $2 \mathrm{~min}, 5 \mu \mathrm{l}$ of drug solution was injected into the lateral ventricle. For the intracerebroventricular and intraperitoneal injections in the free-behaving preparation, the rat was disconnected from the recording apparatus and removed from the recording chamber. The intracerebroventricular injection procedure performed in $<5$ min with minimal stress to the rat, and the rat was immediately returned to the recording chamber for continued data acquisition.

\section{Drugs}

N6-cyclohexyladenosine (CHA; Sigma-Aldrich) was dissolved in isotonic saline to a concentration of $1 \mathrm{~mm}$. Meanwhile, 8-cyclopentyl-1,3dimethylxanthine (CPT; Sigma-Aldrich) was treated with $100 \mathrm{~mm} \mathrm{NaOH}$ and then diluted in $10 \mathrm{~mm}$ PBS to a final concentration of $3 \mathrm{~mm}$. CHA and 
CPT were chosen for these studies based on their high affinities for A1ARs. The GABA $_{\mathrm{A}}$ receptor agonist muscimol (1 mM) and the NMDA receptor agonist NMDA $(0.2 \mathrm{mM})$ were obtained from Tocris Bioscience and diluted in isotonic saline. Atropine (Sigma-Aldrich) was dissolved in sterile isotonic saline at the concentration of $1 \mathrm{mg} / \mathrm{ml}$ and administered intraperitoneally at a dose of $1 \mathrm{mg} / \mathrm{kg}$.

\section{Anatomy}

Serial coronal sections ( $30 \mu \mathrm{m})$ were cut on a freezing-stage microtome, collected sequentially in six sets, and stored in PBS with $0.01 \%$ sodium azide at $4^{\circ} \mathrm{C}$. Sections containing the NTS region of the brainstem from bregma -12 to $-15 \mathrm{~mm}$ were preincubated in an antibody dilution solution (ADS; $500 \mathrm{ml}$ of PBS, $0.3 \%$ Triton X-100, $1.25 \mathrm{~g}$ of carrageenan, $100 \mathrm{mg}$ of $\mathrm{NaN} 3,5 \mathrm{ml}$ of normal donkey serum) for $3 \mathrm{~h}$ and incubated overnight at room temperature with the primary antibodies for c-fos (1:10,000, rabbit anti-c-fos; PC38, Calbiochem) and tyrosine hydroxylase (TH, 1:1500, mouse-anti-TH; 22941, ImmunoStar). A separate set of tissue containing NTS coming from the same group of treated rats $(n=4)$ was incubated overnight at room temperature with the primary antibody for CTb (1:20,000, Goat anti-CTb; 703, List Biological Laboratories). After two washes in PBS containing 0.3\% Triton X-100 (TPBS, 20 $\mathrm{mM}$ ), the tissue was incubated for $1 \mathrm{~h}$ in ADS containing the secondary antibody for c-fos (1:500 AlexaFluor 594-donkey-anti-rabbit; A21207, Invitrogen). After two washes in TPBS, the tissue was incubated for $1 \mathrm{~h}$ in ADS containing the secondary antibody for TH (1:500, AlexaFluor 488donkey-anti-mouse; A21202, Invitrogen). A separate set of tissue treated with the primary antibody for CTb was incubated for $1 \mathrm{~h}$ in ADS containing the secondary antibody (1:500, AlexaFluor 488-donkey-antigoat; A11055, Invitrogen). After fluorescent labeling, the tissue was washed in PBS and mounted onto coated slides, air dried, and coverslipped with antifade mounting medium (Pro-Long Gold, Invitrogen).

\section{Tissue analysis}

The neuroanatomical localization of c-fos-positive, TH-positive, and $\mathrm{CTb}$-positive neurons is based on a stereotaxic rat brain atlas (Paxinos and Watson, 2007). Photomicrographs of brain sections and labeled neurons in the NTS area were taken, for green and red fluorescence, with a camera attached to an Olympus BX51fluorescence microscope. The photomicrographs were assembled into a plate using Adobe Photoshop to adjust contrast and brightness without altering the original colors. Photomicrographs for each section for each rat were resized with Adobe Illustrator CS5.1 to match the dimension of the appropriate Paxinos atlas drawing (Paxinos and Watson, 2007). The counting of the c-fosimmunoreactive (c-fos-ir), TH-immunoreactive (TH-ir), and CTbpositive neurons was performed by an operator unaware of the treatment that the rat received. The counting box (see Fig. 4) was designed to contain the main portion of NTS at the different coronal levels from bregma -15.00 to $-13.56 \mathrm{~mm}$. We excluded from the counting the ependymal and periventricular c-fos-ir cells, even when they fell inside the counting box. For the statistical comparison, counts on the left and right sides of NTS were summed.

\section{Data acquisition}

BAT SNA (1-300 Hz, $1 \mathrm{kHz})$, Tbat $(5 \mathrm{~Hz})$, Tcore $(5 \mathrm{~Hz})$, Tskin $(5 \mathrm{~Hz})$, paw temperature (TPAw; $5 \mathrm{~Hz})$, expired $\mathrm{CO}_{2}, \mathrm{AP}(200 \mathrm{~Hz})$, EEG $(0.1-30$ $\mathrm{Hz}, 500 \mathrm{~Hz})$, EKG $(10-300 \mathrm{~Hz}, 1 \mathrm{kHz})$, EMG $(10-300 \mathrm{~Hz}, 5 \mathrm{kHz})$, and stimulus trigger pulse signals were filtered and digitized (Cyberamp, Molecular Devices; Micro 1401 MKII, Cambridge Electronic Design) and recorded onto a computer hard drive for subsequent analysis (Spike 2, Cambridge Electronic Design). For the BAT SNA, EMG, and EEG, continuous measures ( $4 \mathrm{~s}$ bins) of signal amplitudes were calculated as the root mean square (rms) value of the BAT SNA (square root of the total power in the $0.1-20 \mathrm{~Hz}$ band), EMG (square root of the total power in the $0.1-500 \mathrm{~Hz}$ band), and EEG (square root of the total power in the $0.5-5$ $\mathrm{Hz}$ for the $\delta$ frequency band and 5-9 Hz for the $\theta$ frequency band) from the autospectra of sequential $4 \mathrm{~s}$ segments for each signal.

\section{Data and statistical analysis}

To examine the effects of drug treatments, BAT SNA was normalized to the minimum BAT SNA, recorded under warm conditions (i.e., TCORE $>37^{\circ} \mathrm{C}$ ), and expressed as percentage control. In Experiment 5, BAT SNA was normalized to the maximum BAT SNA recorded during skin cooling, and expressed as a percentage of this cold-evoked BAT SNA. In Experiment 5, the increases in the mean EMG amplitudes during the 2 min window at the peak of the cooling response were normalized to the mean EMG amplitudes during the 2 min window before skin cooling, and expressed as percentage increase above this control. For the EEG in free-behaving rats, the amplitudes of the $\delta$ and $\theta$ frequency bands were calculated in a $1 \mathrm{~h}$ window at the nadir of the CHA-evoked hypothermia, were normalized to the mean respective frequency band amplitudes calculated from the entire $24 \mathrm{~h}$ of EEG recording during the baseline day, and are expressed as percentage increase above the baseline day control amplitudes. For all variables except the EEG, the data were averaged into $30 \mathrm{~s}$ bins for group data analyses and group data are means \pm SEM.

All statistics were performed using Prism software (Version 6, GraphPad Software). Data were considered normally distributed if positive results were obtained using the D'Agostino and Pearson omnibus normality test. Statistical results with $p<0.05$ were considered significant. Post hoc analyses for multiple comparisons were calculated using the Bonferroni correction and corrected $p$ values are reported for each comparison. For Experiment 1 (Fig. 1B), the statistic comparison was made using a $t$ test, after calculating the contribution of the effect of the treatment at each time point considered for the analysis. The statistical comparisons between baseline and post-CHA values and between baseline and saline recording days were performed at the injection time, at the nadir of the effect, and at the end of the recording day, and $p$ values were corrected for six comparisons. The differences in the power spectra after the CHA treatment (Fig. 1C) were tested by using one-way repeatedmeasure ANOVA. For Experiments 2 (Fig. 2), 3 (Fig. 3B-D), and 5 (see Fig. 6), the statistical significance was assessed using a one-tailed, paired $t$ test after testing the data for normality. For each variable, statistical comparisons were made between the 1 min baseline period before the injection and the $1 \mathrm{~min}$ window at the peak or nadir of the treatmentevoked effect. In Experiment 4 (Fig. 4A), the non-normally distributed data were compared using the Friedman nonparametric test to show differences within the treatment groups. Point-by-point comparisons between treatment groups were performed using the nonparametric Mann-Whitney test for unpaired, one-tailed data. $p$ values were not corrected for multiple comparisons. For the c-fos counting (Fig. $4 B$ ), a two-way repeated-measure ANOVA test was used to determine the effect of the treatment and the distribution within the brain sections. In Experiments 6 (see Fig. 7) and 7 (see Fig. 8), the significance of the effect of each treatment was tested using a one-way, repeated-measure ANOVA.

\section{Experimental protocols}

Experiment 1: intracerebroventricular injection of $\mathrm{CHA}$ in free-behaving rats. The experimental protocol consisted of a baseline day of recording at a TAMB of $25^{\circ} \mathrm{C}$, followed by the treatment day in which, at 9 A.M., the TAMB was reduced to $15^{\circ} \mathrm{C}$ and the rats $(n=4)$ received an intracerebroventricular injection of CHA $(5 \mu \mathrm{l}, 1 \mathrm{~mm})$ after $1 \mathrm{~h}$ at TAMB of $15^{\circ} \mathrm{C}$. The changes in TAMB occurred within $10 \mathrm{~min}$ of changing the recording chamber temperature setting. Six hours after the drug injection, the TAMB was set to $28 \pm 1^{\circ} \mathrm{C}$ for the next $18 \mathrm{~h}$, after which it was returned to $25^{\circ} \mathrm{C}$ for $2 \mathrm{~d}$ of recovery recording (Recovery 1 and 2). Subsequently, this protocol was repeated, with the same series of TAMB changes, with a baseline day of control recording followed by a treatment day with an intracerebroventricular injection of saline vehicle (5 $\mu \mathrm{l})$, followed by a recovery day.

Experiment 2: atropine injection in free-behaving rats treated with an intracerebroventricular injection of CHA. The experimental protocol consisted of a baseline day of recording at temperature ТАMB of $25^{\circ} \mathrm{C}$, followed by the treatment day in which, at 9 A.M., the TAMB was reduced to $15^{\circ} \mathrm{C}$ and the rats $(n=4)$ received an intracerebroventricular injection of CHA $(5 \mu \mathrm{l}, 1 \mathrm{~mm}) 1 \mathrm{~h}$ after the ТАмB was changed from $25^{\circ} \mathrm{C}$ to $15^{\circ} \mathrm{C}$. Each rat received an injection of atropine $(1 \mathrm{mg} / \mathrm{kg}$ i.p. $) \sim 1 \mathrm{~h}$ after the occurrence of the first skipped heartbeats. Data were collected for the rest of the day until the rat recovered from the hypothermic state.

Experiment 3: intracerebroventricular injection of CHA in anesthetized rats. Under $2 \%$ isoflurane, one group of rats $(n=12)$ received an intracerebroventricular injection of CHA $(5 \mu \mathrm{l}, 1 \mathrm{~mm})$, under warm $(n=6)$ or 
A

Baseline
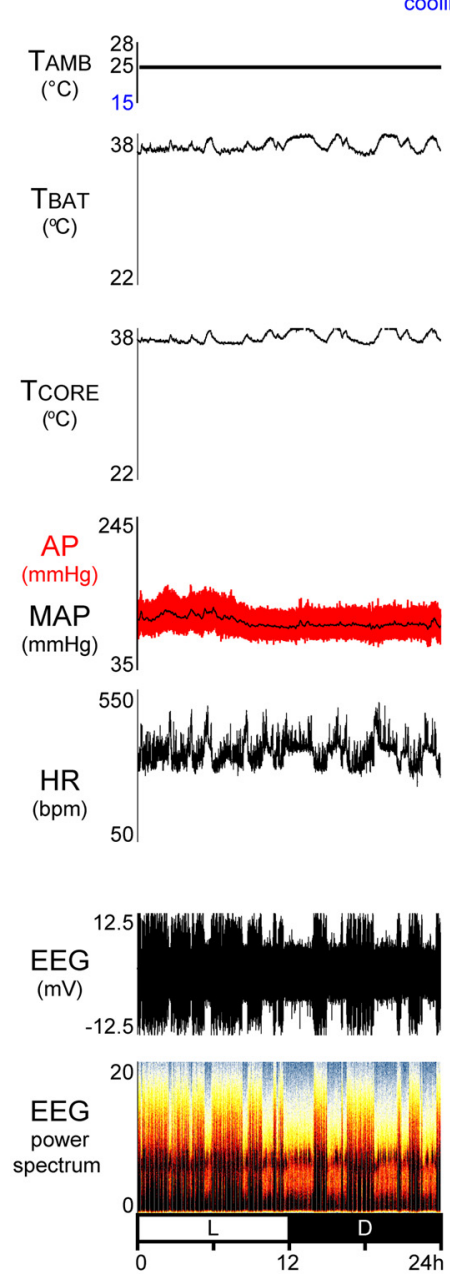

TCORE

$\left({ }^{\circ} \mathrm{C}\right)$

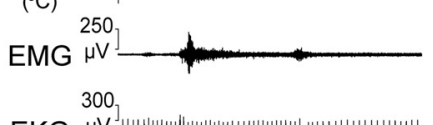

EKG $\mu V^{3}$ Hentw

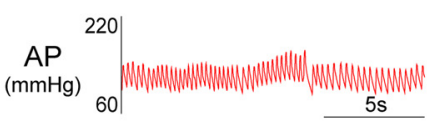

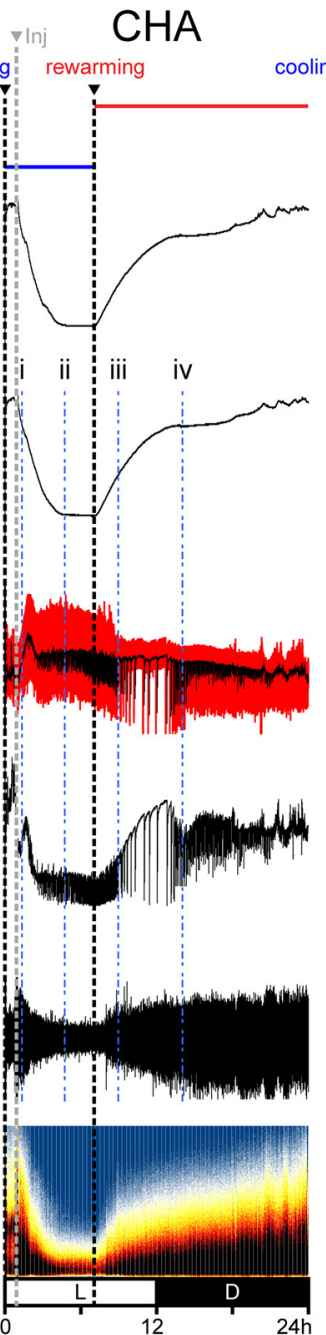

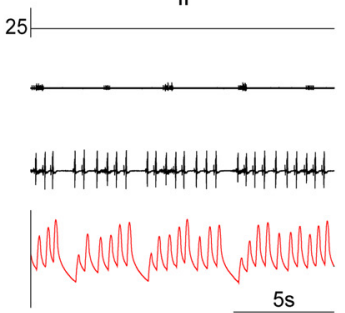

Saline

Yinj Salin

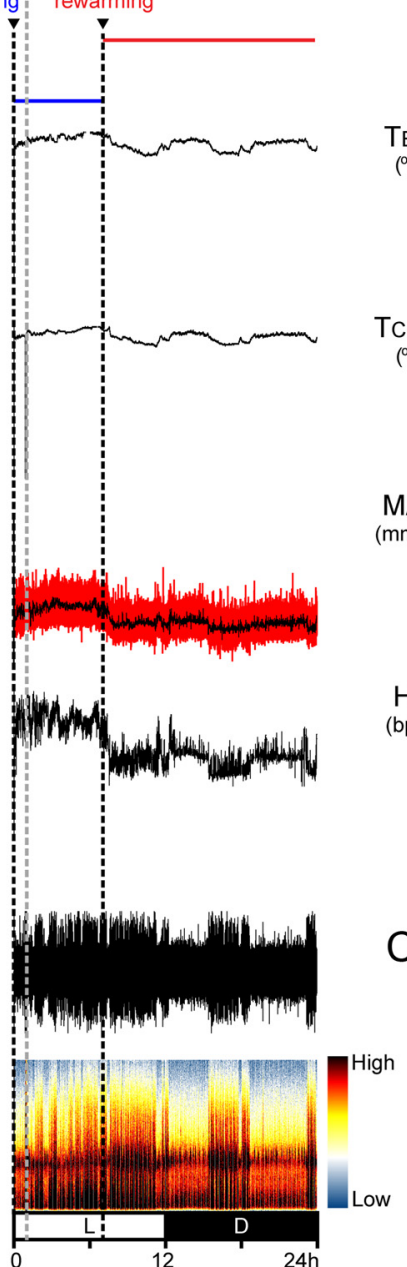

iii

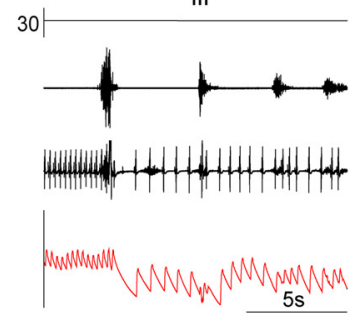

B
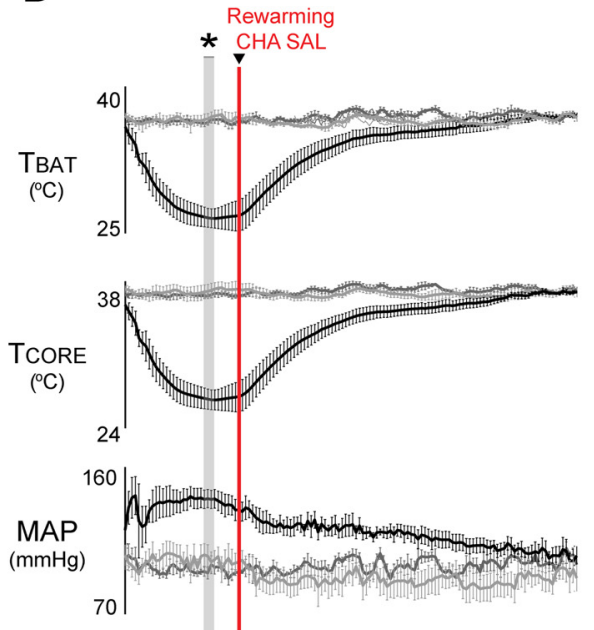

HR

550
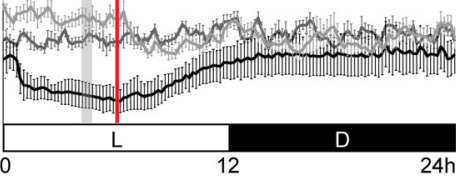

- Baseline - CHA - Saline
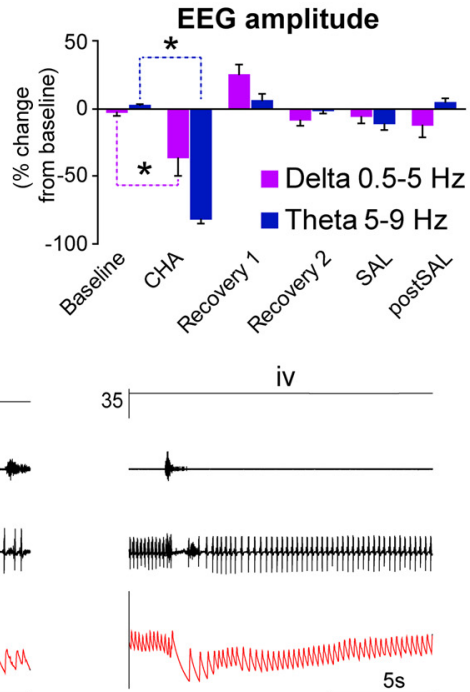

Figure 1. Central activation of A1AR produces a torpor-like state in rat. $\boldsymbol{A}$, Representative recordings from a single rat during three, $24 \mathrm{~h}$ periods: baseline (no treatment), following intracerebroventricular injection of CHA (Inj, gray dashed line), and following intracerebroventricular injection of saline (Inj, gray dashed line). TamB, measured with a thermocouple within the recording chamber, was $25^{\circ} \mathrm{C}$ during the baseline day. During the treatment days, TAmB was initially $15^{\circ} \mathrm{C}$ (cooling, black dashed line) and was increased to $28^{\circ} \mathrm{C}$ (rewarming, black dashed line) at $6 \mathrm{~h}$ after intracerebroventricular CHA and after intracerebroventricular saline. i-iv, Representative recordings of skipped heartbeats and transient bradycardic events, often associated with nucal muscle contraction, at the entrance, nadir, and early and late recovery times ( $\boldsymbol{A}$, blue dotted lines) of the hypothermia produced by the CHA treatment. AP, Pulsatile arterial pressure; MAP, mean arterial pressure; L, light phase; D, dark phase. $\boldsymbol{B}, 24 \mathrm{~h}$ time courses of the physiological variables during the baseline day (light gray), following intracerebroventricular CHA (black) and following intracerebroventricular saline (SAL, dark gray). Data are means $\pm \operatorname{SEM}(n=4){ }^{*} p<0.05$ [comparing the values at the time (gray vertical bar) of the maximal effect of intracerebroventricular CHA with those at the same interval after intracerebroventricular saline]. Red vertical bar indicates the time of the onset of the rewarming period in TAMB. $\boldsymbol{C}$, Normalized (to mean band amplitudes during the $24 \mathrm{~h}$ of the baseline day EEG) amplitudes of $\delta$ and $\theta$ bands of the EEG during the $1 \mathrm{~h}$ period of the maximal effect of the intracerebroventricular (HA and same $1 \mathrm{~h}$ period on other days. The normalized rms amplitudes of the $\delta$ and $\theta$ bands after intracerebroventricular CHA were reduced from those on the baseline day. Data are means \pm SEM. ${ }^{*} p<0.05$ (comparing intracerebroventricular (HA and baseline).

cold skin conditions $(n=6)$. TCORE, Tskin, TPAW, and HR (derived from the EKG) were measured during this protocol. An additional group of rats $(n=5)$, anesthetized with urethane/chloralose, received an intracerebroventricular injection of CHA $(5 \mu \mathrm{l}, 1 \mathrm{~mm})$ while recording BAT SNA, TBAT, expiratory $\mathrm{CO}_{2}, \mathrm{AP}$, and HR.

Experiment 4: c-fos expression following intracerebroventricular CHA. After a week of recovery from the implantation of an intracerebroven- tricular microcannula and iBAT temperature probe, rats $(n=12)$ were housed in a controlled environmental chamber kept at a TAMB of $25^{\circ} \mathrm{C}$. On the day of the experiment, the ТАMB was lowered to $15^{\circ} \mathrm{C}$ and the rats were kept at this ТАМВ for $2 \mathrm{~h}$ before receiving an intracerebroventricular injection of either saline ( $5 \mu \mathrm{l}, 154 \mathrm{~mm}, n=6)$ or CHA $(5 \mu \mathrm{l}, 1 \mathrm{~mm}, n=$ 6 ), until the termination of the experiment. The temperature of iBAT was obtained every $15 \mathrm{~min}$ for the $60 \mathrm{~min}$ before drug injection and then at 5 , 


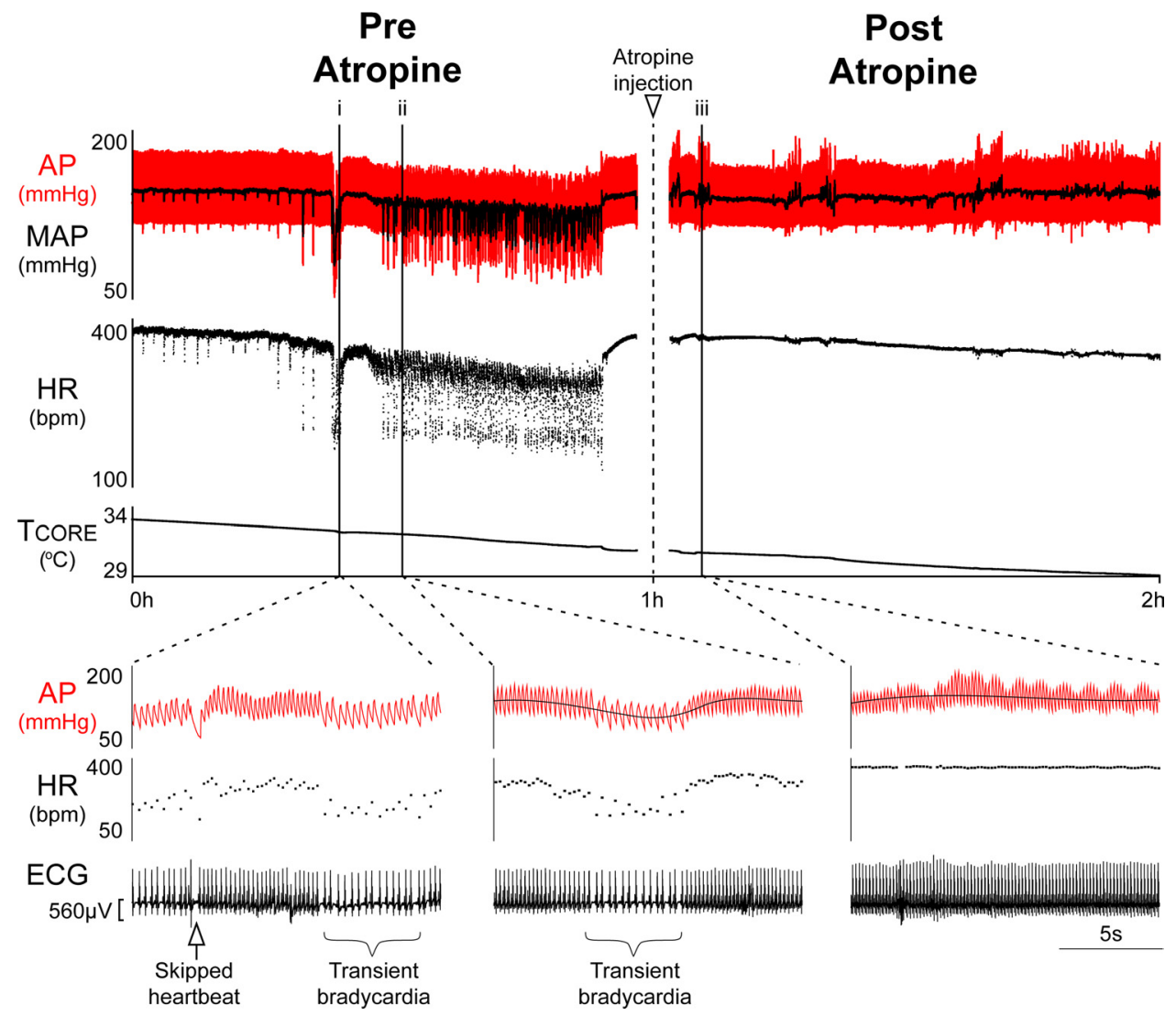

Figure 2. Atropine treatment abolishes skipped heartbeats and transient bradycardia associated with CHA-induced hypothermia. In free-behaving rats, atropine injected intraperitoneally completely abolished (iii) the skipped heartbeats (i, arrow) and transient bradycardia (i, ii, bracket) occurring after the central activation of A1ARs. Time calibration bar represents 5 s in i-iii.

$15,30,45,60$, and 75 min after the injection. A subset of these rats (saline, $n=4$; CHA, $n=4)$ was anesthetized with sodium pentobarbital ( 100 $\mathrm{mg} / \mathrm{kg}$, i.p.) at $2 \mathrm{~h}$ after the injection, perfused with saline followed by $4 \%$ paraformaldehyde, and the brains were removed, postfixed in $4 \%$ paraformaldehyde for $12 \mathrm{~h}$, cryoprotected in $30 \%$ sucrose for $12 \mathrm{~h}$, sectioned, and processed for immunohistochemical localization of c-fos, $\mathrm{TH}$, and $\mathrm{CTb}$.

Experiment 5: sequential nanoinjections of CHA and muscimol in NTS. Under urethane-chloralose anesthesia, rats $(n=8)$ received bilateral intraparenchymal nanoinjections of CHA $(60 \mathrm{nl}, 1 \mathrm{~mm})$ in the iNTS (relative to calamus scriptorius: $0.5 \mathrm{~mm}$ rostral, $0.4 \mathrm{~mm}$ lateral, and 0.4 $\mathrm{mm}$ ventral). We measured the effect of the drug injection on BAT SNA, Tbat, Tcore, Tpaw, Tskin, AP, HR, and expiratory $\mathrm{CO}_{2}$ for $20 \mathrm{~min}$ following the first injection. Twenty minutes after the injection of CHA, five of the eight rats received bilateral nanoinjections of muscimol ( $60 \mathrm{nl}, 1$ $\mathrm{mm}$ ) into the iNTS.

Experiment 6: injection of CPT in NTS. Under urethane-chloralose anesthesia, rats $(n=4)$ received sequential (separated by $10 \mathrm{~min}$ ) bilateral nanoinjections into the iNTS of saline ( $60 \mathrm{nl}, 154 \mathrm{~mm}), \mathrm{CPT}$ ( $60 \mathrm{nl}, 3$ $\mathrm{mm}), \mathrm{CHA}(60 \mathrm{nl}, 1 \mathrm{~mm})$, and NMDA ( $60 \mathrm{nl}, 0.2 \mathrm{~mm})$ in the iNTS. The CPT nanoinjections into iNTS were repeated and followed by an intracerebroventricular injection of CHA $(5 \mu \mathrm{l}, 1 \mathrm{~mm})$.

Experiment 7: nanoinjection of CHA in iNTS inhibits shivering. Under inactin anesthesia, rats $(n=4)$ whose TCORE was maintained $<37^{\circ} \mathrm{C}$ received sequential episodes of skin cooling to elicit increases in EMGs characteristic of shivering (Nakamura and Morrison, 2011). Between successive bouts of skin cooling, rats were treated with bilateral nanoinjections of saline $(60 \mathrm{nl}, 154 \mathrm{~mm})$ or CHA $(60 \mathrm{nl}, 1 \mathrm{~mm})$ into the iNTS while monitoring neck, jaw, and leg EMGs, TвAт, Tcore, Tpaw, Tskin, AP, and HR.

\section{Results}

Central A1AR activation induces a torpor-like state in the rat In chronically instrumented, awake, free-behaving rats maintained in a TAMB of $15^{\circ} \mathrm{C}$, intracerebroventricular injection $(5 \mu \mathrm{l}$, $1 \mathrm{mM}$ ) of the A1AR agonist CHA consistently produced a rapid fall in HR $\left[-213 \pm 46\right.$ beats per minute $(\mathrm{bpm}), t_{(3)}=4.6, p=$ 0.009 ], followed closely by steady declines in TвAт $(-10.3 \pm$ $\left.1.1^{\circ} \mathrm{C}, t_{(3)}=8.7, p=0.0016\right)$ and $\operatorname{TCORE}\left(-10.3 \pm 1.2^{\circ} \mathrm{C}\right.$, $\left.t_{(3)}=8.4, p=0.0017\right)$, increases in mean AP $(+39.5 \pm 6 \mathrm{mmHg}$, $\left.t_{(3)}=-6.4, p=0.003\right)$, and more slowly developing reductions in EEG amplitude, all of which were maintained in an apparent steady-state condition throughout the $6 \mathrm{~h}$ period of exposure to a TAMB of $15^{\circ} \mathrm{C}$ (Fig. $1 A, B$ ). Relative to those occurring at the same time after intracerebroventricular injection of saline vehicle (SAL), intracerebroventricular injection of CHA evoked dramatically reduced minimum values (nadir $\sim 4 \mathrm{~h}$ postinjection) of TCOre $\left(26.7 \pm 0.9^{\circ} \mathrm{C}\right.$ post-CHA vs $37.2 \pm 0.6^{\circ} \mathrm{C}$ post-SAL $)$, TBAT $\left(26.9 \pm 1.6^{\circ} \mathrm{C}\right.$ post-CHA vs $36.8 \pm 0.4^{\circ} \mathrm{C}$ post-SAL), and $\mathrm{HR}$ $(171 \pm 42 \mathrm{bpm}$ post-CHA vs $361 \pm 15 \mathrm{bpm}$ post-SAL; Fig. $1 B)$. The physiological variables at the starting and ending times of each of the 3 recording days were not different among the baseline, CHA treatment, or SAL treatment.

Superimposed on the bradycardia elicited by intracerebroventricular CHA were repeated bouts of irregular HR, characterized by skipped heartbeats (Fig. $1 A$, ii-iv) and transient bradycardias, similar to those described during the onset of torpor hypothermia in 13-lined ground squirrel (Lyman, 1961; Lyman and O'Brien, 1963). At the nadir of the intracerebroventricular CHA- 

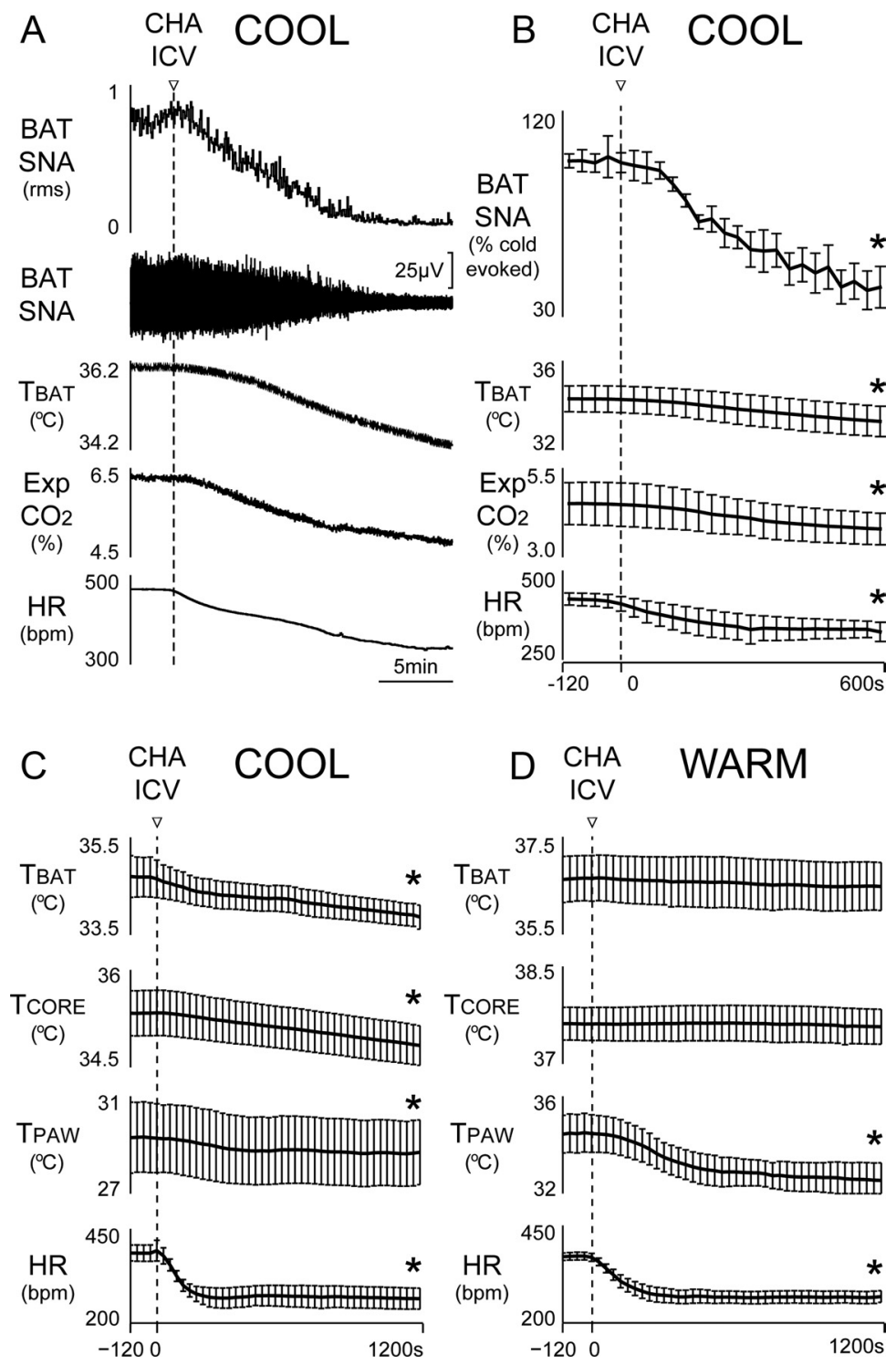

Figure 3. Central administration of CHA inhibits BAT thermogenesis and reduces cutaneous heat loss. $A, B$, In anesthetized rats, intracerebroventricular CHA (dashed line) inhibited the elevated BAT SNA and TвAт evoked by cold exposure and reduced the expired $\mathrm{CO}_{2}\left(\mathrm{Exp} \mathrm{CO}_{2}\right)$ and $\mathrm{HR}$. C, D, Mean responses in anesthetized rats to intracerebroventricular CHA under cool conditions ( $C$ ) and under conditions of a warm TCORE $(\boldsymbol{D})$, the latter accompanied by an increased TPAW, indicative of cutaneous vasodilation. Note that in the warm condition, intracerebroventricular CHA elicits a profound reduction in TPAw, indicating that $C H A$ drives a cutaneous vasoconstriction. Data are means \pm SEM $(B, n=6 ; C, D, n=5) .{ }^{*} p<0.05$ (comparing maximal CHA-evoked changes and pre-CHA injection control values).

evoked hypothermia, the skipped heartbeats occurred frequently, causing a "saw-tooth" appearance to the pulse pressure (Figs. $1 \mathrm{~A}$, iii, 2, i, ii) as also described during natural torpor (Lyman, 1961; Lyman and O'Brien, 1963; Jinka, 2012). As the HR returned to control values during the recovery phase, skipped heartbeats were often associated with nucal muscle contraction and were always followed by long periods of bradycardia (Fig. $1 A$, iii, iv).

Intracerebroventricular $\mathrm{CHA}$ resulted in a modification of the EEG and disruption of the ultradian sleep-wake cycle such that both rapid eye movement (REM) and non-REM (NREM) phases were absent. The amplitudes of both the $\theta$ and $\delta$ frequency bands of the EEG were markedly reduced-an EEG pattern different from that of an NREM or a wake state. At the nadir of the reduction in EEG amplitude following the intracerebroventricular administration of CHA, the rms amplitude of the $\delta$ frequency band $(0.5-5 \mathrm{~Hz})$ of the EEG was significantly reduced $\left(-34 \pm 10.5 \%, t_{(15)}=\right.$ $3.246, p=0.027)$ compared with that during the same time period on the baseline day. The $\theta$ frequency band $(5-9 \mathrm{~Hz}$ ) of the EEG was almost abolished following intracerebroventricular $\mathrm{CHA}$, with the rms amplitude falling by $-84.8 \pm 5.0 \%$ $\left(t_{(15)}=17.0, p<0.0001\right)$ compared with that during the same time period on the baseline day (Fig. 1C). Following the day on which rats receivedintracerebroventricular CHA, $2 \mathrm{~d}$ of recovery preceded the intracerebroventricular SAL day and the post-SAL recovery day. By the first day after intracerebroventricular CHA (Fig. 1C, Recovery 1), the rms amplitudes of both the $\delta$ band $\left(+27.9 \pm 10.5 \%, t_{(15)}=2.655\right.$, $p=0.09)$ and the $\theta$ band $(+3.6 \pm 5.0 \%$, $\left.t_{(15)}=0.7105, p>0.9\right)$ of the EEG were not different from those on the baseline day. Similarly, on the second recovery day, all physiological variables, including EEG amplitude (Fig. 1C, Recovery 2), TCORE, TBAT, HR, and AP were stable and were not different from those on the baseline day (data not shown). Moreover, the sleep behavior of the rats had recovered, as highlighted by the reappearance of normal wake-sleep cycles (wake, NREM, and REM). Compared with the baseline day, intracerebroventricular SAL did not affect the EEG amplitude (Fig. 1C), which also was not different from baseline on the post-SAL recovery day (Fig. $1 C$, post-SAL).

Intracerebroventricular $\mathrm{CHA}$ induced a behavioral state with almost no motor activity and a minimal responsiveness to stimuli, such as sudden noise or innocuous tail pinch. CHA-treated rats did not eat or drink, but urinated occasionally. During the rewarming and throughout their return to euthermia, rats showed normal motor behaviors, drank abundantly, and showed no signs of stress, such as porphyrin accumulation around the eyes. The rats appeared to recover completely from the episode of deep hypothermia, with no obvious differences in behavior or physiological variables between the baseline day and the 2 recovery days, or in the 1 week of observation following the experimental protocol. Curiously, despite having used a larger dose of CHA than in an earlier study in ground squirrels (Jinka et al., 2011), the recovery of the physiological variables began shortly after increasing the TAMB from 15 to $28^{\circ} \mathrm{C}$, suggesting that the recovery was triggered by skin warming rather than by a waning effectiveness of the central CHA.

Atropine eliminates the skipped heartbeats and transient bradycardias induced by the central activation of A1ARs We determined the role of the vagal input to the heart in the skipped heartbeats and transient bradycardias that occurred after the central activation of AlARs. In chronically instrumented, 
A Hypothermia elicited by CHA ICV
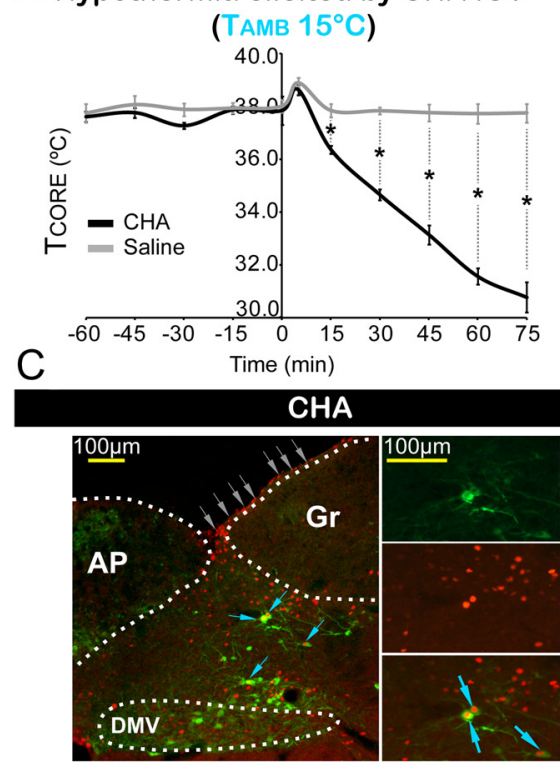

B

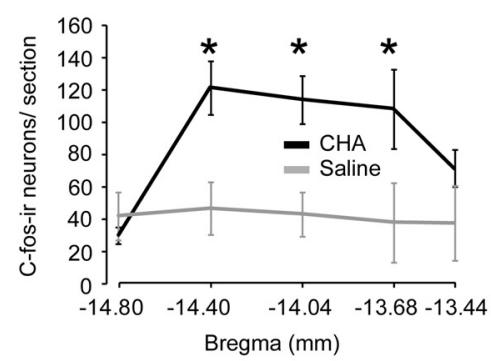

$\mathrm{D}$

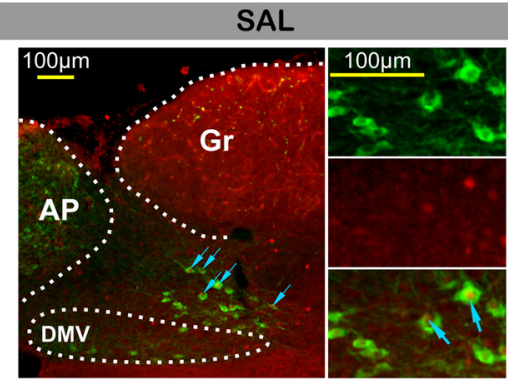

Bregma -14.04 mm
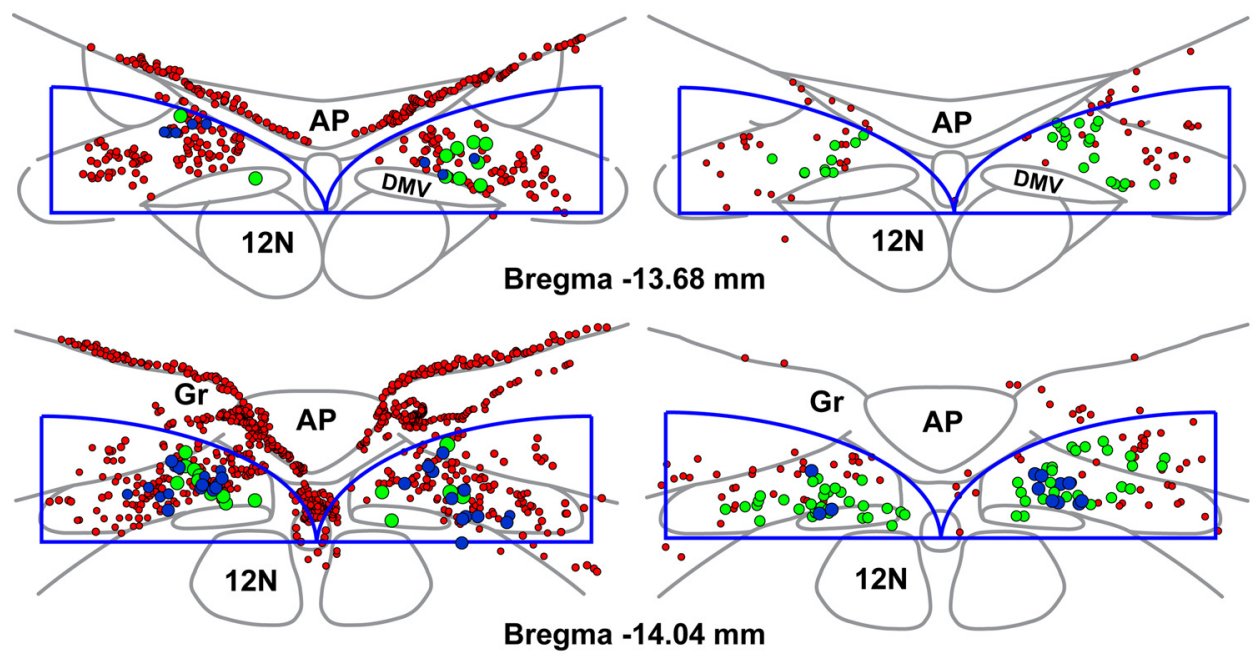

Bregma -14.04 mm
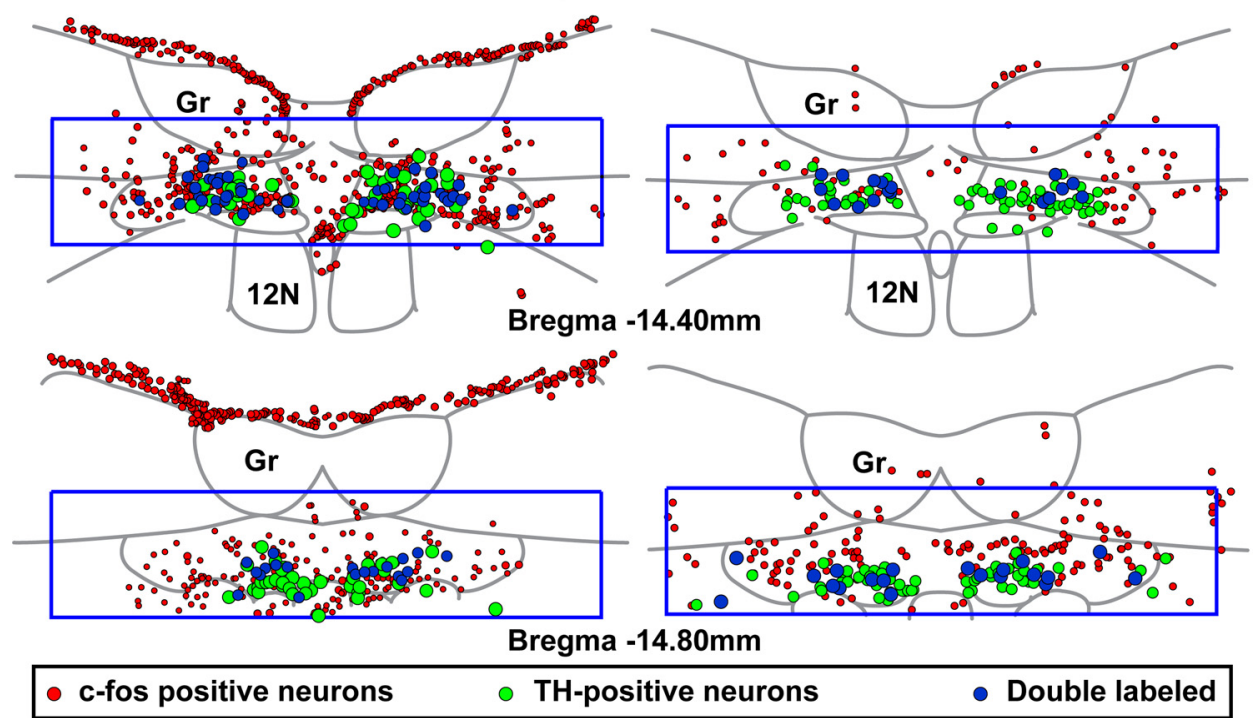

Figure 4. Central administration of $\mathrm{CHA}$ in free-behaving rat produces a profound hypothermia and activates neurons in iNTS. $A$, Reduction in Tcore elicited by intracerebroventricular $C H A$, but not by intracerebroventricular saline (SAL), in awake rats in an ambient temperature (TAMB) of $15^{\circ} \mathrm{C}$. Data are means $\pm \mathrm{SEM}(n=6$ for $\mathrm{CHA}$ and saline). $\boldsymbol{B}$, Counts of $\mathrm{c}$-fos-ir neurons at different levels of iNTS following intracerebroventricular CHA or intracerebroventricular SAL. Data are means \pm SEM ( $n=4$ for CHA and for saline). ${ }^{*} p<0.05$ (comparing the number of (Figure legend continues.) 
free-behaving rats maintained in a TAMB of $15^{\circ} \mathrm{C}$, intracerebroventricular injection $(5 \mu \mathrm{l}, 1 \mathrm{~mm})$ of the A1AR agonist CHA produced a reduction in HR accompanied by skipped heartbeats (Fig. 2, i) and transient bradycardic episodes (Fig. 2, i, ii). One hour after the onset of skipped heartbeats, atropine $(1 \mathrm{mg} / \mathrm{kg}$, i.p.) completely abolished both the skipped heartbeats (Fig. 2, iii; $17 \pm 3$ skipped heartbeats/h before atropine vs 0 skipped heartbeats/h after atropine, $\left.t_{(3)}=5.422, p=0.0062\right)$ and the associated transient bradycardias (compare Fig. 2, i-iii), which remained suppressed throughout the duration of the hypothermic bout and during the recovery phase.

\section{Central A1AR activation inhibits BAT thermogenesis and increases cutaneous vasoconstriction}

To determine whether a central A1AR-mediated inhibition of BAT SNA and BAT thermogenesis contributed to the dramatic hypothermia evoked by intracerebroventricular CHA (Figs. 1A, $3 A$ ), CHA was injected intracerebroventricularly in urethaneanesthetized Wistar rats while recording BAT SNA from small BAT nerve bundles dissected from the ventral surface of the interscapular BAT pad (Tupone et al., 2011; Madden et al., 2013). With the skin cooled to maintain TCORE $<36^{\circ} \mathrm{C}$ and thereby elicit a basal, thermoregulatory level of BAT SNA, intracerebroventricular administration of CHA $(5 \mu \mathrm{l}, 1 \mathrm{~mm})$ evoked a marked bradycardia (baseline HR $417 \pm 18 \mathrm{bpm}$, nadir of $330 \pm 25 \mathrm{bpm}$, $t_{(4)}=5.746, p=0.0023$ ) followed by a reduction in BAT SNA (Fig. $2 A, B ;-56 \pm 10 \%$ of preinjection control, $t_{(4)}=4.158, p=$ 0.0071 ) and an ensuing fall in ТВАТ (baseline $34.3 \pm 0.6^{\circ} \mathrm{C}$, nadir of $\left.33.3 \pm 0.7^{\circ} \mathrm{C}, t_{(4)}=3.196, p=0.0165\right)$, and expired $\mathrm{CO}_{2}$, an indirect indicator of overall metabolism (baseline $4.5 \pm 0.6 \%$, nadir of $\left.3.8 \pm 0.4 \%, t_{(4)}=2.986, p=0.02\right)$.

To determine whether a cutaneous vasoconstriction contributed to the increase in mean AP following intracerebroventricular CHA (Fig. $1 A, B$ ) and because a reduced cutaneous heat loss is a characteristic of hibernation and torpor (Lyman, 1961; Geiser, 2004), we observed the changes in TPAW, an indirect indicator of skin blood flow, after intracerebroventricular CHA in isofluraneanesthetized rats with TCORE maintained in a cool and in a warm condition. With skin cooling and TCORE $<36^{\circ} \mathrm{C}$ (Fig. $3 \mathrm{C}$ ), a condition in which both BAT thermogenesis (Fig. 3A) and cutaneous vasoconstriction are active (Romanovsky et al., 2002), intracerebroventricular administration of CHA $(5 \mu \mathrm{l}, 1 \mathrm{~mm})$ produced immediate decreases in $\operatorname{HR}\left(-119 \pm 27 \mathrm{bpm}, t_{(5)}=4.321 p=\right.$ $0.0038)$, followed by a decrease in Тват $\left(-0.8 \pm 0.2^{\circ} \mathrm{C}, t_{(5)}=\right.$ $4.403 p=0.0035)$ that was accompanied by steady declines in both TCORE $\left(-0.5 \pm 0.1^{\circ} \mathrm{C}, t_{(5)}=5.117, p=0.0019\right)$ and in TPAW $\left(-0.8 \pm 0.3^{\circ} \mathrm{C}, t_{(5)}=2.570, p=0.025\right)$. Since the decline in TPAW under these conditions could have been due either to a CHAstimulated increase in cutaneous vasoconstriction or to a passive fall in TPAw due to the fall in TCORE, we injected CHA intracerebroventricularly in rats with a warm skin and TCORE $>37^{\circ} \mathrm{C}$ to

(Figure legend continued.) $\quad$ c-fos-ir neurons/30 $\mu \mathrm{m}$ section between CHA and SAL treatments). $\boldsymbol{C}, \boldsymbol{D}$, Histological sections from a representative rat (top) and drawings from a rat brain atlas (Paxinos and Watson, 2007) for levels of the iNTS between bregma -13.68 and -14.80 $\mathrm{mm}$ (bottom) showing distributions of c-fos-ir (red nuclei, red dots), TH-ir (green cells, green dots), and double-labeled (blue arrows, blue dots) neurons in iNTS following intracerebroventricular CHA (C) or intracerebroventricular SAL (D). The blue outline in the lower panels represents the area of iNTS from which the cell counts in $\boldsymbol{B}$ were obtained. Intracerebroventricular CHA strongly increased c-fos expression in fourth ventricular ependymal cells (top, gray arrows), but these were excluded from the c-fos-ir cell counts. AP, Area postrema; DMV, dorsal motor nucleus of the vagus; Gr, gracile nucleus; $12 \mathrm{~N}, 12{ }^{\text {th }}$ nerve nucleus. approximate a thermoneutral condition with partial dilation of the cutaneous blood vessels and inhibition of basal thermoregulatory BAT thermogenesis. In warmed rats, intracerebroventricular CHA also produced a fall in $\operatorname{TpAw}\left(-2.4 \pm 1^{\circ} \mathrm{C}, t_{(5)}=2.235\right.$, $p=0.033)$ similar to that in the cooled rats, even though there was no change in either Тват $\left(-0.2 \pm 0.1^{\circ} \mathrm{C}, t_{(5)}=1.858, p=\right.$ $0.06)$ or TCORE $\left(-0.9 \pm 0.6^{\circ} \mathrm{C}, t_{(5)}=1.502, p=0.1935\right)$. Similar to the rats under a cool condition, intracerebroventricular CHA also evoked a large fall in $\mathrm{HR}\left(-105 \pm 13 \mathrm{bpm}, t_{(5)}=7.969, p=\right.$ 0.0003 ) in warmed rats. These data indicate that, in contrast to the inhibition of the SNA driving cold-defensive BAT thermogenesis (Fig. $3 A, B$ ), intracerebroventricular CHA supports colddefensive cutaneous vasoconstrictor sympathetic outflow to reduce heat loss.

\section{NTS neurons are activated by intracerebroventricular administration of $\mathrm{CHA}$}

The iNTS contains a dense localization of A1ARs (Carrettiero and Fior-Chadi, 2004; Pickel et al., 2006) and a potent inhibition of BAT SNA and BAT thermogenesis follows nanoinjection of the $\mathrm{GABA}_{\mathrm{A}}$ antagonist bicuculline into the iNTS (Cao et al., 2010). To determine the potential role of an activation of BAT sympathoinhibitory neurons in iNTS in the hypothermic, torporlike state induced by intracerebroventricular administration of CHA, we tested the hypothesis that iNTS neurons are activated (i.e., express c-fos) during the hypothermia evoked by intracerebroventricular CHA. In rats exposed to a ТАмВ of $15^{\circ} \mathrm{C}$, intracerebroventricular CHA $(5 \mu \mathrm{l}, 1 \mathrm{mM})$, but not intracerebroventricular saline $(5 \mu \mathrm{l}, 154 \mathrm{~mm})$, produced a precipitous fall in TCORE (Fig. 4A) paralleling that seen in the chronically instrumented rats (Fig. $1 B$ ). TCORE in CHA-treated rats was lower than in saline-treated rats at each time point after injection (15 $\min , p=0.0054 ; 30,45,60$, and $75 \mathrm{~min}, p=0.0011$; uncorrected Mann-Whitney test). The number of c-fos-expressing neurons in the $\sim 1300 \mu \mathrm{m}$ extent of the iNTS between bregma -13.5 and $-14.8 \mathrm{~mm}$ (Paxinos and Watson, 2007) was greater in CHAtreated rats than in those receiving intracerebroventricular saline (Fig. 4B--D; two-way repeated measure ANOVA; interaction $F_{(4,24)}=5.041, p=0.0043$; position $F_{(4,24)}=5.688, p=0.0023$; treatment $\left.F_{(1,6)}=5.744, p=0.0535\right)$ for the position relative to bregma of $-14.4 \mathrm{~mm}\left(t_{(30)}=3.020, p=0.0256\right)$, of $-14.04 \mathrm{~mm}$ $\left(t_{(30)}=2.859, p=0.0383\right)$, and of $-13.68 \mathrm{~mm}\left(t_{(30)}=2.838, p=\right.$ $0.0403)$. No differences were observed at bregma $-14.76 \mathrm{~mm}$ $\left(t_{(30)}=0.4840, p>0.9\right)$ or $-13.56 \mathrm{~mm}\left(t_{(30)}=1.371, p>0.9\right)$. CHA (Fig. 4C), but not saline (Fig. 4D), treatment also caused a marked c-fos expression in the ependymal cells lining the fourth ventricle and the central canal. A similar ependymal cell c-fos expression was also reported in the ground squirrel during torpor (Bratincsák et al., 2007) and following peripherally delivered purinergic drug treatment (Dragunow and Faull, 1989). No functional explanation has been ascribed to these observations and we cannot exclude a direct effect of CHA on ependymal cells (Briski and Marshall, 2001).

Some of the catecholaminergic (i.e., TH-ir) neurons in iNTS expressed c-fos following intracerebroventricular administration of CHA and of saline (Fig. 4C,D), but there was no difference in the number of double-labeled (i.e., $\mathrm{TH}+/ \mathrm{c}-$ fos + ) iNTS neurons between the two groups (two-way repeated measure ANOVA, interaction $F_{(4,24)}=3.231, p=0.03$; position $F_{(4,24)}=9.031, p=$ 0.0001 ; treatment $\left.F_{(1,6)}=0.9146, p=0.3758\right)$ measured at the positions relative to bregma of $-14.76 \mathrm{~mm}\left(t_{(30)}=1.302, p>\right.$ $0.9)$, of $-14.4 \mathrm{~mm}\left(t_{(30)}=0.2170, p>0.9\right)$, of $-14.04 \mathrm{~mm}$ 


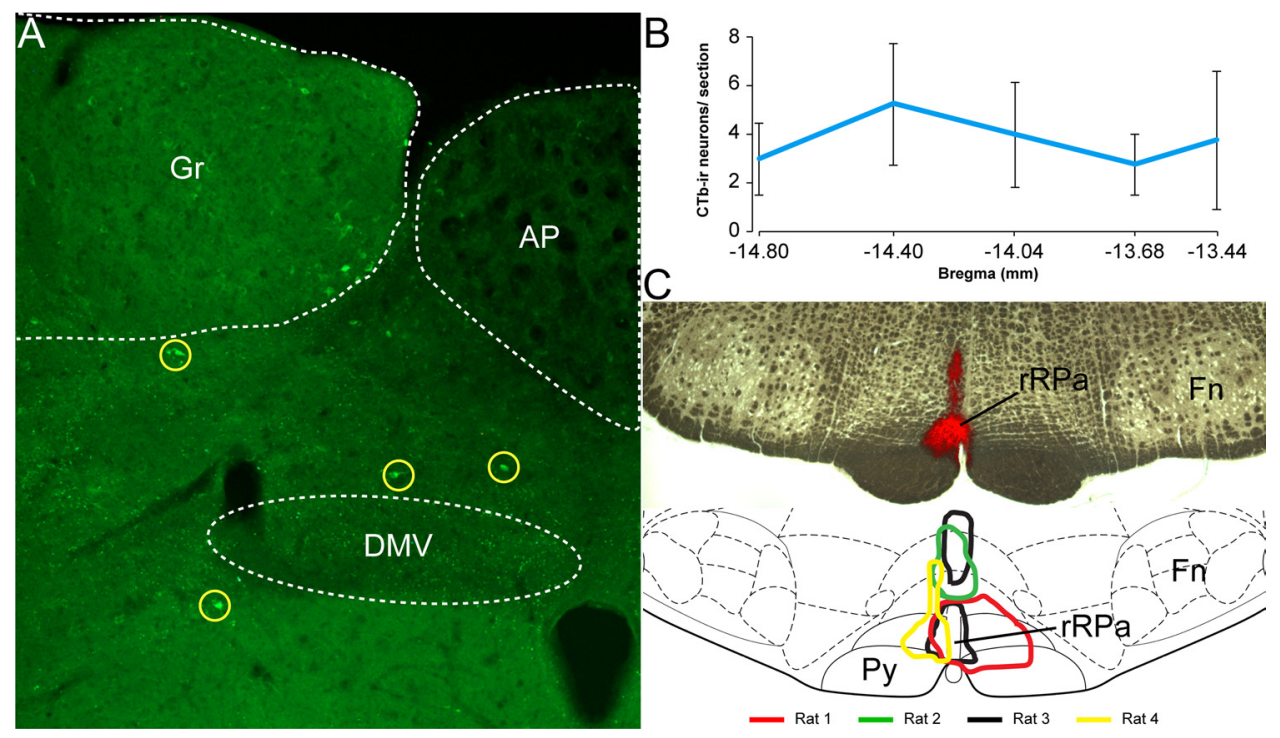

Figure 5. Neurons in iNTS do not project directly to rRPa. A, Histological section through the iNTS from a representative rat showing (Tb-ir neurons (yellow circles) labeled after CTb injections into the rRPa. $B$, Counts of CTb-ir neurons at different levels of iNTS. Data are mean \pm SEM $(n=4)$. C, Schematic diagram showing the CTb injection sites in the rRPa area of four rats. Fn, Facial nucleus; AP, area postema; DMV, dorsal motor nucleus of the vagus; Gr, gracillus nucleus; Py, pyramidal tract.

$\left(t_{(30)}=1.989, p=0.2792\right)$, of $-13.68 \mathrm{~mm}\left(t_{(30)}=1.628 p=\right.$ $0.5702)$, or of $-13.56 \mathrm{~mm}\left(t_{(30)}=1.085 p>0.9\right)$.

To determine whether there was an anatomical substrate for iNTS neurons that were activated by intracerebroventricular CHA to project directly to BAT sympathetic premotor neurons in the $\mathrm{rRPa}$ (Morrison et al., 2012), we injected the retrograde tracer $\mathrm{CTb}$ into the rRPa of four rats. We observed only a few, scattered CTb-ir neurons in the iNTS, averaging $4 \pm 0.5$ cells per $30 \mu \mathrm{m}$ section between bregma -14.8 and $-13.7 \mathrm{~mm}$ and with no consistent clustering (Fig. 5). In agreement with earlier retrograde tracing studies of inputs to $\mathrm{rRPa}$ (Hermann et al., 1997; Yoshida et al., 2009), we conclude that few, if any, iNTS neurons project directly to the rRPa, although we cannot completely exclude the possibility that some iNTS neurons might project to a slightly more caudal extension of the $\mathrm{RPa}$, which also participates in the control of BAT thermogenesis (Cerri et al., 2010).

\section{A1AR activation in iNTS inhibits BAT thermogenesis and reduces TCORE}

The findings that CHA increased the number of c-fos-ir neurons in iNTS and that activation of iNTS neurons produces an inhibition of BAT SNA and BAT thermogenesis (Cao et al., 2010) support the hypothesis that the intracerebroventricular CHAevoked inhibition of thermogenesis and the ensuing fall in TCORE result from an activation of BAT sympathoinhibitory neurons in iNTS. To determine whether direct activation of A1ARs in iNTS inhibits BAT SNA, skin and core cooling (TCORE: $36.2 \pm 0.3^{\circ} \mathrm{C}$, $n=7$ ) were used to induce a basal thermoregulatory level of BAT SNA that was $1100 \pm 306 \%$ of the control BAT SNA when the rats were warm. Subsequent bilateral nanoinjection of CHA (60 nl, 1 $\mathrm{mM}$ ) into the iNTS (Fig. $6 \mathrm{C}$ ) produced a rapid and strong inhibition of cooling-evoked BAT SNA and a long-lasting decline in BAT thermogenesis (Fig. 6A,B). At 20 min following CHA administration, BAT SNA was decreased by $-75 \pm 5 \%$ of the level before CHA injection $\left(t_{(7)}=3.129, p=0.008\right)$. Concomitantly, TвAт fell $-1.2 \pm 0.2^{\circ} \mathrm{C}\left(t_{(7)}=5.290, p=0.0006\right)$, expired $\mathrm{CO}_{2}$ fell $-0.3 \pm 0.1 \%$ from a baseline of $4.8 \pm 0.3 \%\left(t_{(7)}=2.598, p=\right.$ $0.017)$, TCORE fell $-0.2 \pm 0.1^{\circ} \mathrm{C}\left(t_{(7)}=2.077, p=0.04\right)$, HR was reduced $-15 \pm 5 \mathrm{bpm}\left(t_{(7)}=2.773, p=0.014\right)$, and mean AP increased $26 \pm 3 \mathrm{mmHg}\left(t_{(7)}=8.830, p<0.0001\right)$. TPAW was unchanged $(p=0.1)$.

To determine whether the direct injection of CHA caused activation of sympathoinhibitory neurons in iNTS, we made bilateral nanoinjections into iNTS of the $\mathrm{GABA}_{\mathrm{A}}$ agonist muscimol $(60 \mathrm{nl}, 1 \mathrm{~mm})$ after bilaterally nanoinjecting CHA (60 nl, $1 \mathrm{~mm})$ into the iNTS. Muscimol nanoinjection into iNTS (Fig. 6C) reversed the CHA-evoked BAT sympathoinhibition, as well as the CHA-evoked falls in BAT thermogenesis (i.e., ТВАT) and in expired $\mathrm{CO}_{2}$, an indirect measure of overall metabolism (Fig. $6 A, B)$. At 10 min after muscimol nanoinjections into iNTS, BAT SNA was increased $\left(t_{(4)}=4.456, p=0.0056\right)$ to a level that was not different from that before the CHA nanoinjections into iNTS (pre-CHA $724 \pm 184 \%$ vs postmuscimol $1033 \pm 142 \%, t_{(4)}=$ $1.428 p=0.2266)$. The return of BAT SNA was followed by increases in ТвАт $+0.8 \pm 0.3^{\circ} \mathrm{C}\left(t_{(4)}=2.661, p=0.028\right)$ and expired $\mathrm{CO}_{2}+0.3 \pm 0.1 \%\left(t_{(4)}=2.562, p=0.031\right)$ from a baseline of $4.2 \pm 0.2 \%$. Muscimol injections into iNTS did not elicit any changes in TCORE $\left(-0.01 \pm 0.05^{\circ} \mathrm{C}, t_{(4)}=0.1669, p=0.4\right)$, $\mathrm{HR}\left(+7 \pm 5 \mathrm{bpm}, t_{(4)}=1.402, p=0.1\right)$, mean AP $(-6 \pm 8$ $\left.\mathrm{mmHg}, t_{(4)}=0.7304, p=0.2528\right)$, or TpAW $\left(-0.3 \pm 0.2^{\circ} \mathrm{C}, t_{(4)}=\right.$ $1.868, p=0.07)$. Since muscimol nanoinjection is expected to inhibit local neurons with $\mathrm{GABA}_{\mathrm{A}}$ receptors, the finding that muscimol in iNTS reverses the BAT sympathoinhibition elicited by CHA in iNTS is consistent with our proposal, also supported by the finding of CHA-induced c-fos in iNTS neurons (Fig. 4), that CHA elicits an increase in the discharge of iNTS neurons whose activity results in an inhibition of BAT SNA.

\section{Blockade of A1ARs in NTS prevents the CHA-evoked inhibition of BAT thermogenesis}

To confirm the receptor specificity of the BAT sympathoinhibition evoked by CHA, we tested the CHA-evoked inhibition of BAT SNA following pretreatment of the iNTS with the specific A1AR antagonist CPT. When bilaterally nanoinjected into iNTS (Fig. $7 B)$, neither vehicle $(60 \mathrm{nl})$ nor CPT $(120 \mathrm{nl}, 3 \mathrm{~mm})$ had any effect on the measured variables (Fig. $7 A, C$ ). In particular, neither agent evoked a change in the elevated level of BAT SNA elicited by skin and core cooling. In contrast to the nearly com- 

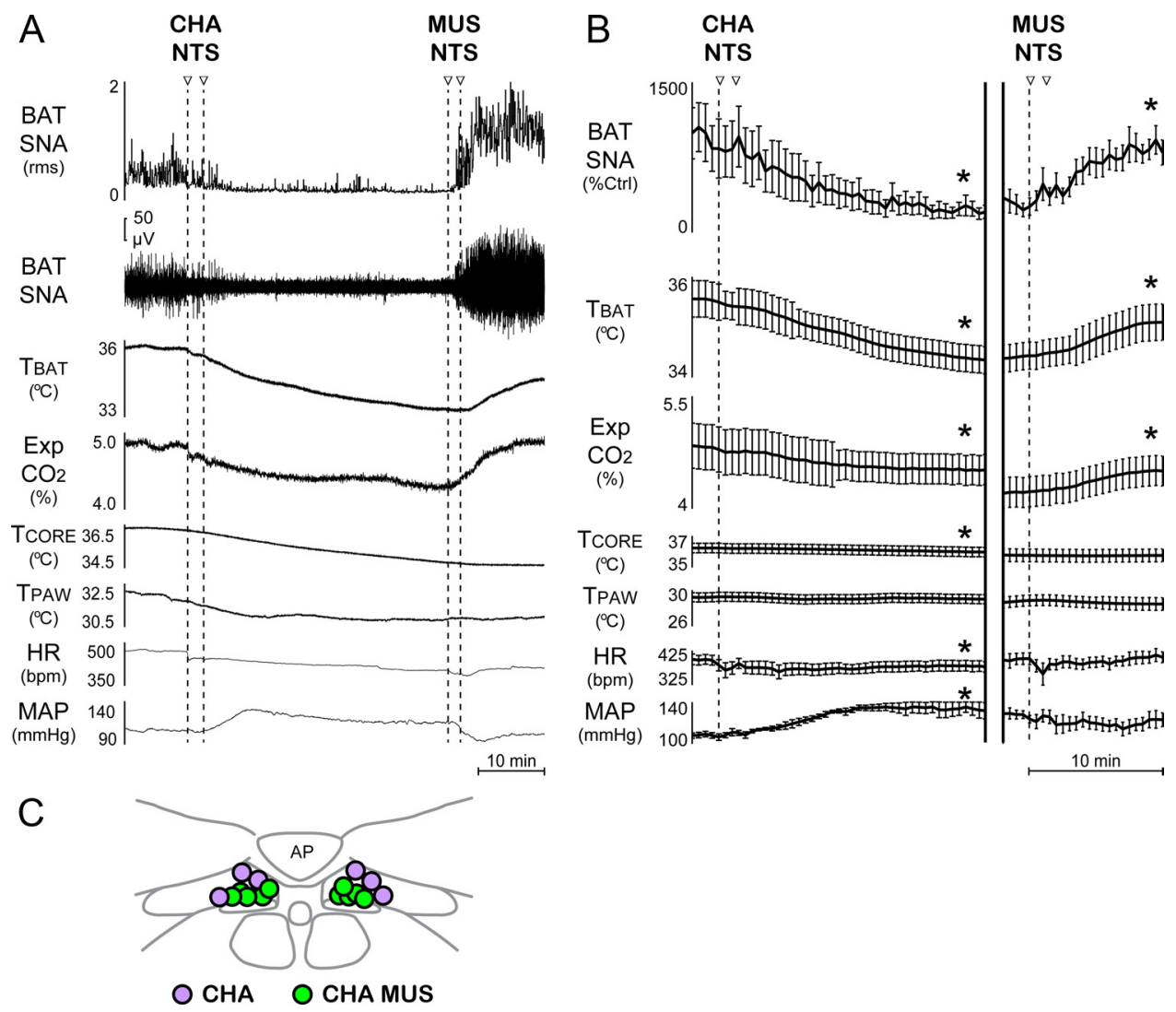

Figure 6. Nanoinjection of CHA into iNTS inhibits BAT thermogenesis and activates iNTS neurons. $A, B$, Cold-evoked BAT SNA and BAT thermogenesis are inhibited by direct bilateral nanoinjections (dotted lines) of CHA into iNTS and reversed by inhibition of iNTS neuronal activity by bilateral nanoinjections of muscimol (MUS) into iNTS illustrated in recordings from a single rat ( $A$ ) and in group data analysis ( $\boldsymbol{B})$. Data are means $\pm \mathrm{SEM}\left(n=8\right.$ for CHA injection, $n=4$ for CHA followed by muscimol injection). ${ }^{*} p<0.05$ [comparing pre-CHA control values and those at 20 min post-CHA (i.e., maximal effect) or comparing premuscimol values and those at 10 min postmuscimol (i.e., maximal effect)]. C, Schematic representation (Paxinos and Watson, 2007) of the bilateral nanoinjection sites in the subpostremal iNTS of CHA only (purple) and CHA and muscimol (green).

plete inhibition of BAT SNA following CHA nanoinjection into iNTS in the absence of CPT pretreatment (Fig. 6), the level of BAT SNA was unchanged by bilateral nanoinjections of CHA $(60 \mathrm{nl}, 1 \mathrm{~mm})$ into iNTS following CPT injections into iNTS (baseline: $108 \pm 7 \%$ vs CHA $107 \pm 18 \%, t_{(23)}=0.07, p>0.9$ ). Excitation of local iNTS neurons with bilateral nanoinjections of the excitatory amino acid NMDA ( $60 \mathrm{nl}, 0.2 \mathrm{~mm})$ evoked a prompt and nearly complete inhibition of BAT SNA ( $-94 \pm$ $\left.18 \%, t_{(23)}=5.039, p=0.0002\right)$. This result, indicating the maintained excitability of BAT sympathoinhibitory neurons in iNTS, suggests that CPT did not produce a generalized inhibition of local iNTS neurons, but rather a specific blockade of local A1AR-mediated responses. Subsequent intracerebroventricular administration of CHA $(5 \mu \mathrm{l}, 1 \mathrm{~mm})$ following bilateral nanoinjection of CPT ( $120 \mathrm{nl}, 3 \mathrm{~mm})$ into iNTS also did not change any of the measured variables, including BAT SNA, which, at $10 \mathrm{~min}$ following the intracerebroventricular administration of CHA, was not different from the baseline level before any iNTS injections (baseline $108 \pm 7 \%$ vs CHA $\left.108 \pm 3 \%, t_{(23)}=0.03, p>0.9\right)$. These data demonstrate that A1AR activation in iNTS is necessary for the BAT sympathoinhibitory effect of locally administered CHA, as well as that of CHA administered intracerebroventricularly (Fig. 3A). Together with the result exemplified in Figure 6, the demonstration that activation of iNTS neurons elicits an inhibition of BAT SNA (Fig. 7, NMDA response), and the finding that blockade of $\mathrm{GABA}_{\mathrm{A}}$ receptors in iNTS produces an inhibition of BAT SNA (Cao et al., 2010), these data are consistent with a model in which the BAT sympathoinhibitory effect of A1ARs in iNTS is due to a disinhibition of local BAT sympathoinhibitory neurons arising from a presynaptic effect of CHA to reduce GABA release onto these neurons.

\section{A1AR activation in iNTS inhibits shivering}

In addition to BAT, shivering thermogenesis is also engaged by central thermoregulatory networks to combat falls in TCORE during exposure to a cold ambient environment (Nakamura and Morrison, 2011). Thus, we hypothesized that central A1AR activation, in particular within the iNTS, would also inhibit cooling-evoked shivering. Episodes of skin cooling $\left(\Delta\right.$ TsKIN, $\sim-4.5^{\circ} \mathrm{C}$; TCORE, $\left.<36^{\circ} \mathrm{C}\right)$ following the injection of saline vehicle into iNTS produced increases in the EMGs of the jaw, neck, and leg muscles that were not different from those evoked by similar episodes of skin cooling applied before saline injection (Fig. 8). Activation of local A1ARs with bilateral nanoinjections of CHA (60 nl, $1 \mathrm{~mm}$ ) into iNTS (Fig. $8 \mathrm{C}$ ) markedly reduced the skin cooling-evoked shivering in the jaw $\left(-99 \pm 0.1 \%, t_{(4)}=5.954, p=0.002\right)$ and neck $(-96 \pm 2 \%$, $\left.t_{(4)}=3.556, p=0.011\right)$ muscles, but not in the leg muscle. Speculatively, the finding that CHA into the iNTS failed to inhibit shivering selectively in the leg could arise from a somatotopic organization of NTS neurons that inhibit shivering, or perhaps a requirement for activation of a greater number of shivering-inhibiting neurons in NTS to inhibit larger muscles in the leg compared with smaller muscles in the neck or jaw. 


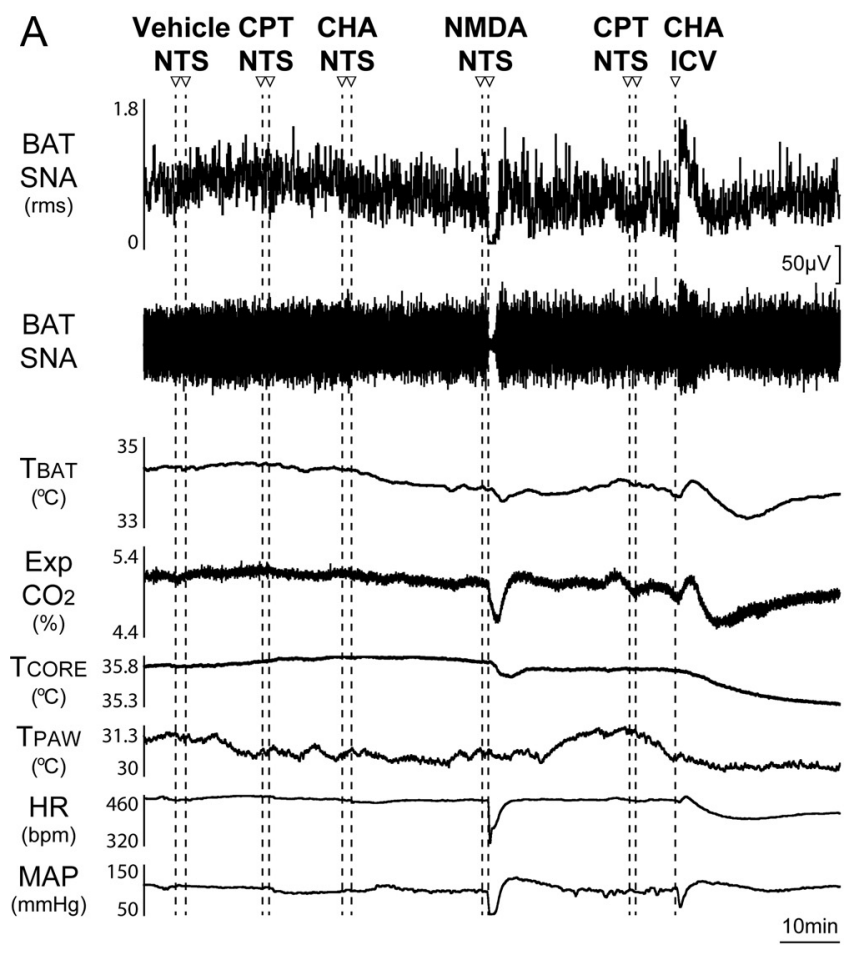

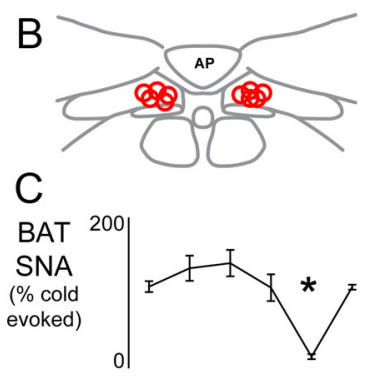
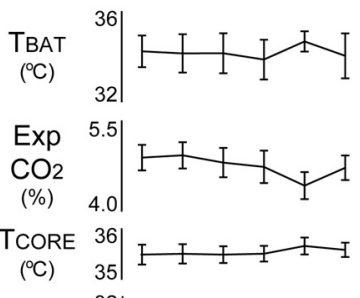

$\begin{array}{cc}\text { TPAW } & 32 \\ \left({ }^{\circ} \mathrm{C}\right) & 28\end{array}$

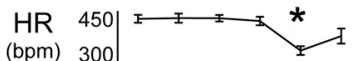

MAP 150

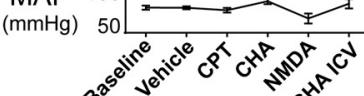

Figure 7. Blockade of A1ARs in iNTS prevents the inhibition of BAT thermogenesis elicited by CHA. $A$, Illustrative recordings from a single anesthetized rat illustrating the effects on BAT SNA, TBAT, and other physiological variables of sequential nanoinjections into iNTS of vehicle (for CPT), CPT, CHA, NMDA, and of CPT, followed by the intracerebroventricular injection of CHA. $B$, Bilateral injection sites (red circles) in iNTS are plotted on an atlas drawing (Paxinos and Watson, 2007) through iNTS. C, Data are means \pm SEM ( $n=5$ for each treatment except $n=4$ for intracerebroventricular injection of $\mathrm{CHA}$ ). ${ }^{*} p<0.05$ (comparing pre-NMDA injection values and post-NMDA values). For the NMDA treatment, comparison was between 1 min of data at baseline, before vehicle injection in iNTS, and $1 \mathrm{~min}$ of data at the nadir of the effect. All other statistical assessments of treatment effects were made between 1 min of baseline, prevehicle injection data and 1 min of data at 10 min after each treatment.

\section{Discussion}

Our principal finding is that although rats are a nonhibernating mammal, when they are maintained in a cool ambient environment, central activation of A1ARs produces a deep hypothermic state that resembles torpor in several respects, including a major reduction in core body temperature and indices of metabolism. The significant fall in TCORE is due mainly to the central A1ARevoked reduction in metabolic heat production, initiated and sustained by the inhibition of cold-defensive BAT and shivering thermogenesis, complemented by the subsequent fall in cellular metabolism occurring as body temperature falls. We discovered that neurons located in the iNTS play a key role in the A1ARmediated hypothermic, torpor-like state: A1ARs in iNTS drive a central inhibition of BAT and shivering thermogenesis, which suspends critical cold-defense mechanisms and allows TCORE to fall to levels dependent on the ТАмв.

This A1AR-mediated inhibition of thermogenesis likely arises from activation of the BAT sympathoinhibitory pathway emanating from iNTS that was initially revealed by the potent inhibition of BAT SNA and BAT thermogenesis following neuronal disinhibition in iNTS (Cao et al., 2010). A1ARs are characterized as inhibitory receptors since their activation on synaptic terminals inhibits neurotransmitter release, while their somatic activation decreases excitability via GIRK channel activation (Wetherington and Lambert, 2002). Thus, A1AR-mediated inhibition of BAT and shivering thermogenesis could be accomplished by A1AR inhibition of tonic GABA release (Ulrich and Huguenard, 1995; Pickel et al., 2006) onto thermogenesisinhibitory iNTS neurons (Cao et al., 2010), allowing an increase in their discharge and a consequent inhibition of BAT and shivering thermogenesis. Consistent with this model are the findings that A1ARs are localized in the iNTS (Carrettiero and FiorChadi, 2004), including on GABAergic terminals (Pickel et al., 2006); that intracerebroventricular CHA elicits increased c-fos expression in iNTS neurons (Fig. 4), that local nanoinjection of CHA into iNTS inhibits BAT SNA (Fig. 6) and shivering (Fig. 8), and that A1AR blockade in iNTS prevents the inhibition of BAT thermogenesis evoked by intracerebroventricular CHA (Fig. 7). While the latter observation indicates that A1AR activation in iNTS is required for the inhibition of thermogenesis that leads to the hypothermia following intracerebroventricular CHA, it does not preclude parallel A1AR-mediated effects at other central thermoregulatory sites (Morrison et al., 2008). Thus, although intracerebroventricular AMP produces hypothermia (Muzzi et al., 2013), the finding that AMP alters the discharge of preoptic area neurons in vitro (Muzzi et al., 2013) does not indicate that preoptic area neurons play a role in AMP-evoked hypothermia since intracerebroventricular AMP would also activate A1ARs in iNTS. Additionally, not all thermally responsive neurons in the preoptic area are involved in thermoregulation, but may play a role in EEG state changes (Berner and Heller, 1998), a dramatic characteristic (Fig. 1) of the central A1AR-evoked, torpor-like state.

The A1AR-evoked inhibition of BAT and of shivering thermogenesis likely arises from the inhibition of the sympathetic and somatic premotor neurons in $\mathrm{rRPa}$ that control these colddefense thermal effectors (Nakamura and Morrison, 2011; Morrison et al., 2012). Indeed, inhibition of rRPa neurons produces 
A
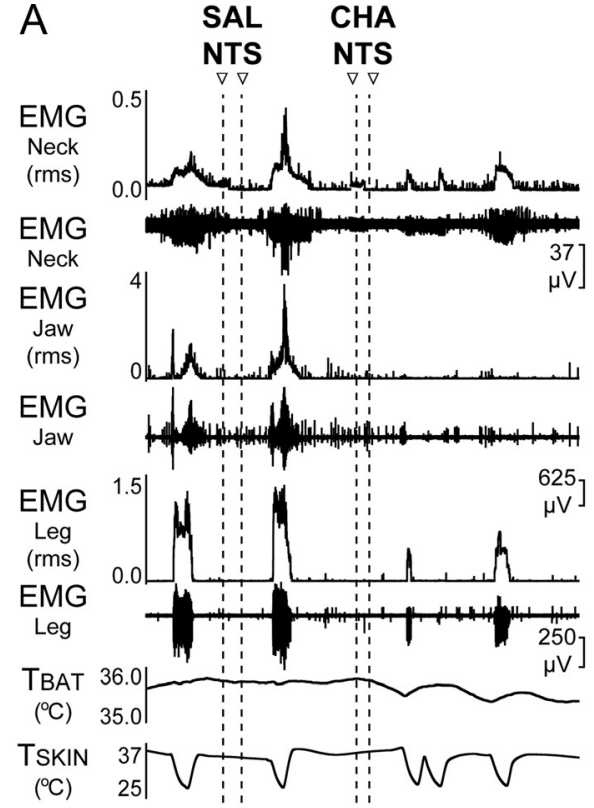

TCORE 36

( $\left.{ }^{\circ} \mathrm{C}\right) \quad 35.0$

HR 470

(bpm) 420

MAP 170

$(\mathrm{mmHg}) 100$

C

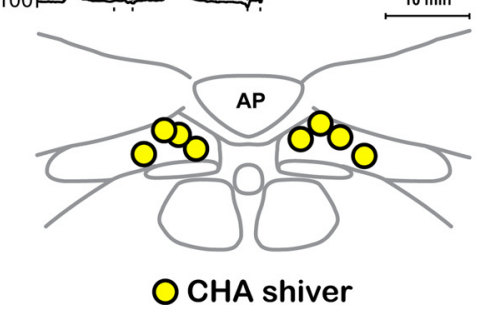

B
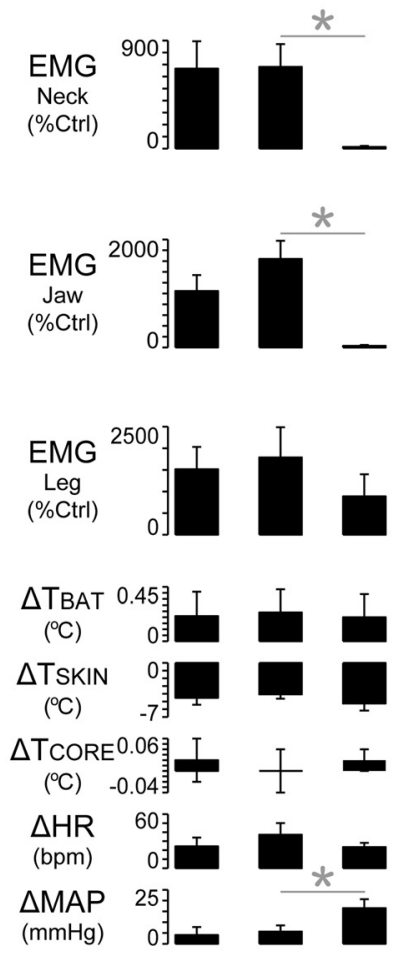

Figure 8. CHA nanoinjection into iNTS inhibits shivering EMG activity. $A, B$, Inhibition of cold-evoked shivering EMGs following bilateral nanoinjections (dotted lines) of $\mathrm{CHA}$, but not saline into iNTS in a single, representative rat $(\boldsymbol{A})$ and in group data analysis (B). Data are means \pm SEM $(n=4) .{ }^{*} p<0.05$ (comparing pre-CHA and post-SAL values). C, Schematic representation (Paxinos and Watson, 2007) of the bilateral nanoinjection sites (yellow circles) of CHA into iNTS.

hypothermia (Cerri et al., 2013) similar to that following central CHA administration. However, we found no anatomical support for a direct projection from the rat iNTS to the rRPa, as recently suggested in the mouse (Kong et al., 2012). Thus, the inhibition of BAT and shivering thermogenesis evoked from the iNTS likely results from activation of a multisynaptic pathway between iNTS and $\mathrm{rRPa}$ that produces either (1) a direct inhibition of $\mathrm{rRPa}$ thermal effector premotor neurons, such as that from ventrolateral medullary neurons (Madden et al., 2013), or (2) an inhibition of an excitatory input to these rRPa premotor neurons, such as that from the dorsomedial hypothalamus (Nakamura and Morrison, 2007, 2011), which is essential for the cold-defense activations of BAT and shivering thermogenesis.

Both the inhibition of thermogenesis evoked by intracerebroventricular CHA and naturally occurring torpor (Lyman, 1961; Lyman and O'Brien, 1963; Heller et al., 1977; Milsom et al., 1999; Geiser, 2004) are accompanied by an increased cutaneous vasoconstriction, suggesting a unique thermoregulatory paradigm in which a reduced metabolic heat production allows TCORE to fall to low levels, simultaneous with a maintained cutaneous vasoconstriction that would slow heat loss and limit the rate of fall of TCORE. A1AR activation in iNTS increases AP (McClure et al.,
2011) due to vasopressin secretion (McClure et al., 2009) and to increased vasoconstriction, including in the cutaneous bed (McClure et al., 2005). These effects could arise from a reduced effectiveness of the baroreceptor reflex elicited by A1AR activation in NTS (Scislo et al., 2008), a finding that also argues against a baroreceptor reflex relationship between the CHA-evoked increase of AP and the accompanying bradycardia. Bradycardia is also a consistent response to A1AR activation in iNTS (Barraco et al., 1991; Scislo et al., 2001) and is an initial physiological manifestation of both natural torpor (Lyman, 1961; Milsom et al., 1999; Jinka, 2012) and central administration of CHA (Figs. 1, 3, 6). In both of the latter cases, the bradycardia is associated with periods of irregular HR, characterized by skipped heartbeats and frequent episodes of transient bradycardia (Fig. 2). The skipped heartbeats and subsequent transient bradycardic episodes following intracerebroventricular CHA were vagally mediated since they were eliminated by atropine, as were similar skipped heartbeats and bradycardia occurring during natural torpor (Lyman and O'Brien, 1963; Milsom et al., 1999). Since these vagally mediated, skipped heartbeats and transient bradycardias were most often associated with nucal muscle EMG bursts, we speculate that they represent respiratory sinus arrhythmias initiated by respiratory gasping events (Huang et al., 2006) reflected in the nucal muscle bursts.

Paralleling naturally occurring torpor, the physiological state induced by central AlARs is characterized by a marked shift from euthermic, cardiorespiratory, and metabolic homeostasis to a hypothermic, hypometabolic, bradycardic steady state in which the EEG amplitude is significantly reduced (Benington et al., 1995; Deboer and Tobler, 1995; Deboer, 1998) and thus different from a sleep state. Neurons in the NTS can also influence the EEG (Golanov and Reis, 2001) and likely mediate the anticonvulsive effects of vagal stimulation (Magdaleno-Madrigal et al., 2010). Central A1AR activation in rodents produces EEG synchronization (Ticho and Radulovacki, 1991; Benington and Heller, 1995; Schwierin et al., 1996; PorkkaHeiskanen et al., 2003; Saper et al., 2005) and thalamic A1AR activation suppresses EEG amplitude (Ulrich and Huguenard, 1995). Whether the changes in EEG evoked by intracerebroventricular CHA in awake rats is dependent on A1AR activation in NTS remains to be assessed.

Adenosine release in NTS may also contribute to the compensatory responses to hypoxia (Yan et al., 1995), hemorrhage (Scislo and O'Leary, 2006), or hypoglycemia (Haas and Selbach, 2000), circumstances in which a reduced metabolic energy consumption (Madden and Morrison, 2005; Madden, 2012) could reduce tissue damage and promote survival. A chronic activation of A1ARs in NTS could reduce energy expenditure and induce a metabolic imbalance predisposing to obesity. In this regard, both 
chronic sleep deprivation (Knutson and Van Cauter, 2008; Van Cauter et al., 2008) and the hypoxic exposure of sleep apnea (Panossian and Veasey, 2012) are significantly correlated with obesity and with elevated central adenosine levels (PorkkaHeiskanen et al., 2000; Elmenhorst et al., 2009; PorkkaHeiskanen and Kalinchuk, 2011). The sources of endogenous A1AR ligand and the circumstances under which the A1AR activated by our CHA administration are normally activated remain to be determined. Indeed, it may be that species that are not naturally torpid, never simultaneously activate the wide distribution of A1ARs activated by our intracerebroventricular administration.

In conclusion, activation of central A1ARs leads to a hypometabolic, torpor-like state in the nonhibernating rat. This hypothermia is dependent on a potent inhibition of cold-defensive BAT and shivering thermogenesis mediated by A1AR activation in the iNTS. Although the contribution of A1ARs in the iNTS to other aspects of the central A1AR-generated, torpor-like state remains to be determined, the coincidence of the wide array of homeostatic physiological and behavioral functions influenced by the NTS and those that are "reset" during natural torpor, in combination with the significant role of A1AR activation in the induction and maintenance of natural torpor (Jinka et al., 2010; Iliff and Swoap, 2012), are consistent with a key role for elevated adenosine, or AMP (Muzzi et al., 2013), in the NTS in initiating the altered homeostatic and behavioral state in natural torpor. These results provide a window into a novel central mechanism for the regulation of metabolism and suggest a novel approach to producing a hypometabolic state in nonhibernating species, including human, with potential therapeutic applications in brain or myocardial ischemia, traumatic brain injury, or lifethreatening fever.

\section{References}

Andresen MC, Kunze DL (1994) Nucleus tractus solitarius-gateway to neural circulatory control. Annu Rev Physiol 56:93-116. CrossRef Medline

Barraco RA, el-Ridi MR, Ergene E, Phillis JW (1991) Adenosine receptor subtypes in the brainstem mediate distinct cardiovascular response patterns. Brain Res Bull 26:59-84. CrossRef Medline

Benington JH, Heller HC (1995) Restoration of brain energy metabolism as the function of sleep. Prog Neurobiol 45:347-360. CrossRef Medline

Benington JH, Kodali SK, Heller HC (1995) Stimulation of A1 adenosine receptors mimics the electroencephalographic effects of sleep deprivation. Brain Res 692:79-85. CrossRef Medline

Berner NJ, Heller HC (1998) Does the preoptic anterior hypothalamus receive thermoafferent information? Am J Physiol 274:R9-R18. Medline

Blevins JE, Schwartz MW, Baskin DG (2004) Evidence that paraventricular nucleus oxytocin neurons link hypothalamic leptin action to caudal brain stem nuclei controlling meal size. Am J Physiol Regul Integr Comp Physiol 287:R87-R96. CrossRef Medline

Bratincsák A, McMullen D, Miyake S, Tóth ZE, Hallenbeck JM, Palkovits M (2007) Spatial and temporal activation of brain regions in hibernation: c-fos expression during the hibernation bout in thirteen-lined ground squirrel. J Comp Neurol 505:443-458. CrossRef Medline

Briski KP, Marshall ES (2001) Induction of ependymal, glial, and neuronal transactivation by intraventricular administration of the SGLT1 Na+-Dglucose cotransporter inhibitor phlorizin. Neurochem Res 26:783-792. CrossRef Medline

Cannon B, Nedergaard J (2004) Brown adipose tissue: function and physiological significance. Physiol Rev 84:277-359. CrossRef Medline

Cao WH, Madden CJ, Morrison SF (2010) Inhibition of brown adipose tissue thermogenesis by neurons in the ventrolateral medulla and in the nucleus tractus solitarius. Am J Physiol Regul Integr Comp Physiol 299: R277-R290. CrossRef Medline

Carrettiero DC, Fior-Chadi DR (2004) Adenosine A1 receptor distribution in the nucleus tractus solitarii of normotensive and spontaneously hypertensive rats. J Neural Transm 111:465-473. CrossRef Medline
Cerri M, Zamboni G, Tupone D, Dentico D, Luppi M, Martelli D, Perez E, Amici R (2010) Cutaneous vasodilation elicited by disinhibition of the caudal portion of the rostral ventromedial medulla of the free-behaving rat. Neuroscience 165:984-995. CrossRef Medline

Cerri M, Mastrotto M, Tupone D, Martelli D, Luppi M, Perez E, Zamboni G, Amici R (2013) The inhibition of neurons in the central nervous pathways for thermoregulatory cold defense induces a suspended animation state in the rat. J Neurosci 33:2984-2993. CrossRef Medline

Deboer T (1998) Brain temperature dependent changes in the electroencephalogram power spectrum of humans and animals. J Sleep Res 7:254262. CrossRef Medline

Deboer T, Tobler I (1995) Temperature dependence of EEG frequencies during natural hypothermia. Brain Res 670:153-156. CrossRef Medline

Dragunow M, Faull RL (1989) Rolipram induces c-fos protein-like immunoreactivity in ependymal and glial-like cells in adult rat brain. Brain Res 501:382-388. CrossRef Medline

Elmenhorst D, Basheer R, McCarley RW, Bauer A (2009) Sleep deprivation increases A(1) adenosine receptor density in the rat brain. Brain Res 1258: 53-58. CrossRef Medline

Geiser F (2004) Metabolic rate and body temperature reduction during hibernation and daily torpor. Annu Rev Physiol 66:239-274. CrossRef Medline

Golanov EV, Reis DJ (2001) Neurons of nucleus of the solitary tract synchronize the EEG and elevate cerebral blood flow via a novel medullary area. Brain Res 892:1-12. CrossRef Medline

Grill HJ, Hayes MR (2012) Hindbrain neurons as an essential hub in the neuroanatomically distributed control of energy balance. Cell Metab 16: 296-309. CrossRef Medline

Haas HL, Selbach O (2000) Functions of neuronal adenosine receptors. Naunyn Schmiedebergs Arch Pharmacol 362:375-381. CrossRef Medline

Heller HC, Colliver GW, Bread J (1977) Thermoregulation during entrance into hibernation. Pflugers Arch 369:55-59. CrossRef Medline

Hermann DM, Luppi PH, Peyron C, Hinckel P, Jouvet M (1997) Afferent projections to the rat nuclei raphe magnus, raphe pallidus and reticularis gigantocellularis pars alpha demonstrated by iontophoretic application of choleratoxin (subunit b). J Chem Neuroanat 13:1-21. CrossRef Medline

Huang ZG, Griffioen KJ, Wang X, Dergacheva O, Kamendi H, Gorini C, Bouairi E, Mendelowitz D (2006) Differential control of central cardiorespiratory interactions by hypercapnia and the effect of prenatal nicotine. J Neurosci 26:21-29. CrossRef Medline

Iliff BW, Swoap SJ (2012) Central adenosine receptor signaling is necessary for daily torpor in mice. Am J Physiol Regul Integr Comp Physiol 303: R477-R484. CrossRef Medline

Jinka TR (2012) Natural protection against cardiac arrhythmias during hibernation: significance of adenosine. In: Cardiac arrhythmias-new considerations (Breijo-Marquez FR, ed). New York: InTech.

Jinka TR, Carlson ZA, Moore JT, Drew KL (2010) Altered thermoregulation via sensitization of $A 1$ adenosine receptors in dietary-restricted rats. Psychopharmacology (Berl) 209:217-224. CrossRef Medline

Jinka TR, Tøien $\varnothing$, Drew KL (2011) Season primes the brain in an arctic hibernator to facilitate entrance into torpor mediated by adenosine $A_{1}$ receptors. J Neurosci 31:10752-10758. CrossRef Medline

Knutson KL, Van Cauter E (2008) Associations between sleep loss and increased risk of obesity and diabetes. Ann N Y Acad Sci 1129:287-304. CrossRef Medline

Kong D, Tong Q, Ye C, Koda S, Fuller PM, Krashes MJ, Vong L, Ray RS, Olson DP, Lowell BB (2012) GABAergic RIP-Cre neurons in the arcuate nucleus selectively regulate energy expenditure. Cell 151:645-657. CrossRef Medline

Lyman CP (1961) The myocardium-its biochemistry and biophysics. III. Hibernation in animals. Hibernation in mammals. Circulation 24:434445. CrossRef Medline

Lyman CP, O'Brien RC (1963) Autonomic control of circulation during the hibernating cycle in ground squirrels. J Physiol 168:477-499. Medline

Madden CJ (2012) Glucoprivation in the ventrolateral medulla decreases brown adipose tissue sympathetic nerve activity by decreasing the activity of neurons in raphe pallidus. Am J Physiol Regul Integr Comp Physiol 302:R224-R232. CrossRef Medline

Madden CJ, Morrison SF (2005) Hypoxic activation of arterial chemoreceptors inhibits sympathetic outflow to brown adipose tissue in rats. J Physiol 566:559-573. CrossRef Medline

Madden CJ, Tupone D, Cano G, Morrison SF (2013) $\alpha 2$ Adrenergic 
receptor-mediated inhibition of thermogenesis. J Neurosci 33:20172028. CrossRef Medline

Magdaleno-Madrigal VM, Martínez-Vargas D, Valdés-Cruz A, AlmazánAlvarado S, Fernández-Mas R (2010) Preemptive effect of nucleus of the solitary tract stimulation on amygdaloid kindling in freely moving cats. Epilepsia 51:438-444. CrossRef Medline

McClure JM, O'Leary DS, Scislo TJ (2005) Stimulation of NTS A1 adenosine receptors evokes counteracting effects on hindlimb vasculature. Am J Physiol Heart Circ Physiol 289:H2536-H2542. CrossRef Medline

McClure JM, Rossi NF, Chen H, O'Leary DS, Scislo TJ (2009) Vasopressin is a major vasoconstrictor involved in hindlimb vascular responses to stimulation of adenosine $\mathrm{A}(1)$ receptors in the nucleus of the solitary tract. Am J Physiol Heart Circ Physiol 297:H1661-H1672. CrossRef Medline

McClure JM, O’Leary DS, Scislo TJ (2011) Neural and humoral control of regional vascular beds via Al adenosine receptors located in the nucleus tractus solitarii. Am J Physiol Regul Integr Comp Physiol 300:R744-R755. CrossRef Medline

Melvin RG, Andrews MT (2009) Torpor induction in mammals: recent discoveries fueling new ideas. Trends Endocrinol Metab 20:490-498. CrossRef Medline

Milsom WK, Zimmer MB, Harris MB (1999) Regulation of cardiac rhythm in hibernating mammals. Comp Biochem Physiol A Mol Integr Physiol 124:383-391. CrossRef Medline

Morrison SF, Nakamura K, Madden CJ (2008) Central control of thermogenesis in mammals. Exp Physiol 93:773-797. CrossRef Medline

Morrison SF, Madden CJ, Tupone D (2012) Central control of brown adipose tissue thermogenesis. Front Endocrin (Lousanne) 3.pii:00005. Medline

Muzzi M, Blasi F, Masi A, Coppi E, Traini C, Felici R, Pittelli M, Cavone L, Pugliese AM, Moroni F, Chiarugi A (2013) Neurological basis of AMPdependent thermoregulation and its relevance to central and peripheral hyperthermia. J Cereb Blood Flow Metab 33:183-190. CrossRef Medline

Nakamura K, Morrison SF (2007) Central efferent pathways mediating skin cooling-evoked sympathetic thermogenesis in brown adipose tissue. Am J Physiol Regul Integr Comp Physiol 292:R127-R136. Medline

Nakamura K, Morrison SF (2011) Central efferent pathways for colddefensive and febrile shivering. J Physiol 589:3641-3658. CrossRef Medline

Panossian LA, Veasey SC (2012) Daytime sleepiness in obesity: mechanisms beyond obstructive sleep apnea-a review. Sleep 35:605-615. Medline

Paxinos G, Watson C (2007) The rat brain in stereotaxic coordinates, 6th edition. San Diego: Academic.

Pickel VM, Chan J, Linden J, Rosin DL (2006) Subcellular distributions of adenosine $\mathrm{A} 1$ and $\mathrm{A} 2 \mathrm{~A}$ receptors in the rat dorsomedial nucleus of the solitary tract at the level of the area postrema. Synapse 60:496-509. CrossRef Medline

Porkka-Heiskanen T, Kalinchuk AV (2011) Adenosine, energy metabolism and sleep homeostasis. Sleep Med Rev 15:123-135. CrossRef Medline

Porkka-Heiskanen T, Strecker RE, McCarley RW (2000) Brain sitespecificity of extracellular adenosine concentration changes during sleep deprivation and spontaneous sleep: an in vivo microdialysis study. Neuroscience 99:507-517. CrossRef Medline

Porkka-Heiskanen T, Kalinchuk A, Alanko L, Urrila A, Stenberg D (2003) Adenosine, energy metabolism, and sleep. ScientificWorldJournal 3:790-798. CrossRef Medline
Romanovsky AA, Ivanov AI, Shimansky YP (2002) Selected contribution: ambient temperature for experiments in rats: a new method for determining the zone of thermal neutrality. J Appl Physiol 92:2667-2679. Medline

Saper CB, Scammell TE, Lu J (2005) Hypothalamic regulation of sleep and circadian rhythms. Nature 437:1257-1263. CrossRef Medline

Schwierin B, Borbély AA, Tobler I (1996) Effects of N6-cyclopentyladenosine and caffeine on sleep regulation in the rat. Eur J Pharmacol 300:163-171. CrossRef Medline

Scislo TJ, O'Leary DS (2006) Adenosine receptors located in the NTS contribute to renal sympathoinhibition during hypotensive phase of severe hemorrhage in anesthetized rats. Am J Physiol Heart Circ Physiol 291: H2453-H2461. CrossRef Medline

Scislo TJ, Kitchen AM, Augustyniak RA, O'Leary DS (2001) Differential patterns of sympathetic responses to selective stimulation of nucleus tractus solitarius purinergic receptor subtypes. Clin Exp Pharmacol Physiol 28:120-124. CrossRef Medline

Scislo TJ, Ichinose TK, O'Leary DS (2008) Stimulation of NTS Al adenosine receptors differentially resets baroreflex control of regional sympathetic outputs. Am J Physiol Heart Circ Physiol 294:H172-H182. Medline

Sessler DI (2009) Defeating normal thermoregulatory defenses: induction of therapeutic hypothermia. Stroke 40:e614-621. CrossRef Medline

Sgoifo A, Stilli D, Medici D, Gallo P, Aimi B, Musso E (1996) Electrode positioning for reliable telemetry ECG recordings during social stress in unrestrained rats. Physiol Behav 60:1397-1401. CrossRef Medline

Székely M (2000) The vagus nerve in thermoregulation and energy metabolism. Auton Neurosci 85:26-38. CrossRef Medline

Ticho SR, Radulovacki M (1991) Role of adenosine in sleep and temperature regulation in the preoptic area of rats. Pharmacol Biochem Behav 40:33-40. CrossRef Medline

Tupone D, Madden CJ, Cano G, Morrison SF (2011) An orexinergic projection from perifornical hypothalamus to raphe pallidus increases rat brown adipose tissue thermogenesis. J Neurosci 31:15944-15955. CrossRef Medline

Ulrich D, Huguenard JR (1995) Purinergic inhibition of GABA and glutamate release in the thalamus: implications for thalamic network activity. Neuron 15:909-918. CrossRef Medline

Van Cauter E, Spiegel K, Tasali E, Leproult R (2008) Metabolic consequences of sleep and sleep loss. Sleep Med 9 [Suppl 1]:S23-S28. CrossRef Medline

Wetherington JP, Lambert NA (2002) Differential desensitization of responses mediated by presynaptic and postsynaptic $A_{1}$ adenosine receptors. J Neurosci 22:1248-1255. Medline

Yan S, Laferrière A, Zhang C, Moss IR (1995) Microdialyzed adenosine in nucleus tractus solitarii and ventilatory response to hypoxia in piglets. J Appl Physiol 79:405-410. Medline

Yenari MA, Han HS (2012) Neuroprotective mechanisms of hypothermia in brain ischaemia. Nat Rev Neurosci 13:267-278. CrossRef Medline

Yoshida K, Li X, Cano G, Lazarus M, Saper CB (2009) Parallel preoptic pathways for thermoregulation. J Neurosci 29:11954-11964. CrossRef Medline

Zhao H, Steinberg GK, Sapolsky RM (2007) General versus specific actions of mild-moderate hypothermia in attenuating cerebral ischemic damage. J Cereb Blood Flow Metab 27:1879-1894. CrossRef Medline 